\title{
Growth expectations, undue optimism, and short-run fluctuations
}

\author{
-Preliminary- \\ Zeno Enders, Michael Kleemann, and Gernot J. Müller*
}

February 2, 2015

\begin{abstract}
We assess the contribution of "undue optimism" (Pigou) to business-cycle fluctuations. In our analysis, optimism (or pessimism) pertains to total factor productivity which determines long-run economic activity. We develop a new strategy to estimate the effects of optimism shocks - autonomous, but fundamentally unwarranted changes in the assessment of productivity. Specifically, we show that by including survey-based nowcast errors regarding current output growth in a VAR model, it is possible to identify optimism shocks. These shocks, in line with theory, generate negative nowcast errors, but raise economic activity in the short run. They account for about 30 percent of short-run fluctuations.
\end{abstract}

Keywords: Undue optimism, optimism shocks, noise shocks, animal spirits, business cycles, nowcast errors, VAR, long-run restrictions

JEL-Codes: E32

*Enders: University of Heidelberg, zeno.enders@uni-heidelberg.de. Kleemann: Ifo Institute and LMU Munich, kleemann@ifo.de. Müller: University of Bonn, CEPR, and Ifo institute, gernot.mueller@unibonn.de. We thank Olivier Blanchard, Olivier Coibion, Kristoffer Nimark, Franck Portier, and participants in various seminars and conferences for helpful comments as well as Kerstin Gärtner and Tobias Anger for research assistance. Part of this research was conducted while Enders was visiting the International Monetary Fund, the hospitality of which is gratefully acknowledged. The views expressed in this paper do not necessarily reflect those of the IMF or IMF policy. 


\section{Introduction}

Economic outcomes depend on expectations and vice versa. In this paper, we ask to what extent changes of expectations are an autonomous source of business cycle fluctuations. This question dates back to Pigou (1927) who discusses the possibility that "errors of undue optimism or undue pessimism" are a genuine cause of "industrial fluctuations". Keynes' notion of "animal spirits" is a related, but distinct concept. ${ }^{1}$ More recently, Beaudry and Portier (2004) explore the possibility of "Pigou cycles" in a quantitative business cycle model featuring possibly undue expectations regarding future productivity. Lorenzoni (2009), in turn, puts forward a model in which misperceptions regarding the current state of productivity turn out to be an important source of business cycle fluctuations.

In this paper, we take up the issue empirically and investigate the contribution of undue optimism and pessimism to business cycles fluctuations. Estimating a vector autoregression (VAR) on U.S. time-series data, we seek to identify "optimism shocks", that is, changes in expectations due to a perceived change in total factor productivity which does not actually materialize. ${ }^{2}$ Blanchard et al. (2013) show that this constitutes a formidable challenge, because optimism shocks or, quite generally, misperceptions are mistakes of market participants. As such they cannot be uncovered by an econometrician who enjoys no informational advantage over market participants. While Blanchard et al. thus advocate structural estimation of misperception models (see also Barsky and Sims 2012), we suggest an alternative approach to account for this insight.

We show that it is possible to identify optimism shocks within a VAR framework by relying on an ex-post measure of agents' misperceptions, namely the nowcast error regarding current output growth. Drawing on the Survey of Professional Forecasters (SPF), we compute it as the difference between actual output growth in a given quarter and the median of the predicted values in real time. A positive realization of the nowcast error thus implies that nowcasts have been too pessimistic. Yet it is important to keep in mind that, as a reduced-form measure, nowcast errors may be the result not only of optimism shocks, but of other structural innovations too.

The SPF is a widely recognized measure of private sector expectations regarding the current state and prospects of the U.S. economy. It is also a frequently used benchmark to assess

\footnotetext{
${ }^{1}$ Keynes' animal spirits are "a spontaneous urge to action rather than inaction", which drive economic decisions beyond considerations based "on nothing but a mathematical expectation" (Keynes 1936, pp. 161 and 162).

${ }^{2}$ Throughout, we refer to these changes in expectations as "optimism shocks" with the understanding that realizations may be positive (optimism shocks) or negative (pessimism shocks).
} 
forecasting models. Nevertheless, as we show in the first step of our analysis, nowcast errors can be sizable. Depending on whether we consider the first or the final release of data for actual output growth, the largest nowcast error exceeds 1 or 1.75 percentage points of quarterly output growth respectively. We also document that nowcast errors are positively correlated with economic activity and investigate how they respond to wellknown measures of structural innovations. We find that innovations which are publicly observable, such as monetary and fiscal policy shocks or uncertainty shocks (as measured by stock market volatility), do not cause nowcast errors. In contrast, technology shocks have a significant effect on nowcast errors, presumably because they impact current output growth, but are not observable by market participants in real time.

Nowcast errors play a key role in our analysis as they allow us to recover optimism shocks from actual time series data. We establish this result within a business cycle model which mimics, in a stylized way, the informational friction which gives rise to nowcast errors. The model is a version of the dispersed-information model of Lorenzoni (2009), for which we are able to obtain closed-form solutions. Using the model, we also derive the identification restrictions on which we rely in the main part of our analysis. Specifically, drawing on earlier work by Galí (1999) and others, we estimate a VAR model on time-series data for labor productivity, employment, and the nowcast error. In order to identify the distinct contributions of optimism and technology shocks to short-run fluctuations, we assume, in line with our theoretical results, that nowcast errors may emerge only as a result of optimism or technology shocks. Yet optimism shocks, in contrast to technology shocks, have no bearing on labor productivity in the long run.

According to the estimated VAR model, optimism shocks - as predicted by theory -induce a negative nowcast error, yet significantly boost economic activity at the same time. This result is noteworthy, because we do not restrict the response of the nowcast error to optimism shocks. Moreover, as the unconditional correlation between nowcast errors and economic activity is positive, the change of the correlation conditional on optimism shocks lends additional support to our identification strategy. Instead, technology shocks induce a positive nowcast error while stimulating economic activity. These results are robust across a range of alternative specifications, including alternative measures of the nowcast error and identification assumptions. Finally, computing a forecast error variance decomposition, we find that optimism shocks account for up to 30 percent of output fluctuations.

Conceptually, our analysis relates to a number of recent studies of the role of exogenous shifts in expectations as a source of business cycle fluctuations. Angeletos and La'O (2013) 
develop a model where "sentiment shocks" arise, as market participants are unduly but simultaneously optimistic about their terms of trade. These shocks trigger aggregate fluctuations even if productivity is known to be constant. ${ }^{3}$ A number of contributions have focused on the distinction between unexpected and anticipated productivity shocks. Evidence by Beaudry and Portier (2006) suggests that business cycles are largely driven by expected future changes in productivity (see also Beaudry et al. 2011, Schmitt-Grohé and Uribe 2012, and Leduc and Sill 2013), while Barsky and Sims (2011) find the role of expected productivity innovations to be limited. To the extent that anticipated shocks do not materialize as expected, a recession might ensue, which is thus caused by undue optimism (Jaimovic and Rebelo 2009). Forni et al. (2014) identify such "noisy news" in a VAR framework which permits identifying structural shocks through a dynamic combination of current as well as future VAR residuals. The authors show within a structural model that it is possible to identify "noisy news", if there are no fundamental surprise shocks. In our analysis, instead, we allow misperceptions to pertain also to current fundamentals.

We also stress that there are more attempts to identify optimism shocks empirically without imposing a fully structural model on the data. Blanchard (1993) provides an animal-spirits account of the 1990-91 recession focusing on consumption. Caroll et al. (1994) show that consumer sentiment forecasts consumption spending - aside from the information contained in other available indicators. Yet in concluding they suggest a "fundamental explanation" based on habits and precautionary saving motives. Oh and Waldman (1990) show that "false macroeconomic announcements", identified as measurement error in early releases of leading indicators, cause future economic activity. They refrain from a structural interpretation, however. Mora and Schulstad (2007) show that once announcements regarding current growth are taken into account, the actual growth rate has no predictive power in determining future growth. Finally, Bachmann and Sims (2012) explore the importance of confidence for the transmission of fiscal shocks, but do not analyze the effect of exogenous variations in confidence.

The remainder of the paper is organized as follows: The next section introduces our measure of nowcast errors and provides a number of statistics illustrating their properties. Section 3 puts forward a simple model which allows us to clarify issues pertaining to the notion of optimism shocks and their identification. Section 4 presents our VAR model and results. A final section concludes.

\footnotetext{
${ }^{3}$ Within a VAR framework Angeletos et al. (2014) construct a single shock which is responsible for the bulk of short-run fluctuations. This shock has features quite distinct from shocks operating in conventional business cycle models. Rather it has the flavor of a sentiment or confidence shock.
} 


\section{A reduced-form measure of misperceptions}

We eventually aim to uncover the effects of optimism shocks, that is, perceived changes in total factor productivity which do not actually materialize. In this section, as a step towards this end, we consider a reduced-form measure of misperceptions by computing nowcast errors regarding current U.S. output growth. Nowcast errors can be the result of optimism shocks, but they may also be due to other structural innovations. Still, nowcast errors will play a key role in our identification strategy in Section 4 below. In what follows, we therefore describe the construction of nowcast errors and compute a number of statistics in order to illustrate their scope, possible causes, and their relation to economic activity.

\section{$2.1 \quad$ Data}

Our main data source is the SPF, initiated by the American Statistical Association and the NBER in 1968Q4, now maintained at the Federal Reserve Bank of Philadelphia. ${ }^{4}$ The survey is conducted at quarterly frequency. Panelists receive the questionnaires at the end of the first month of the quarter and have to submit their answers by the 2nd to $3 \mathrm{rd}$ week of the following month. The results of the survey are released immediately afterwards. At this stage, no information regarding current output is available from the Bureau of Economic Analysis (BEA). At most, in order to nowcast output growth for the current quarter, forecasters may draw on the NIPA advance report regarding output in the previous quarter.

Predicted quarterly output growth is annualized and measured in real terms. Note that initially, within the SPF, output is measured by GNP, later by GDP. We compute nowcast errors by subtracting the survey's median forecast from the actual value reported later by the BEA. ${ }^{5}$ We compute two measures of nowcast errors by distinguishing between the first and the final data release for actual output growth. ${ }^{6}$ For the latter, we use the latest

\footnotetext{
${ }^{4}$ Professional forecasters are mostly private, financial-sector firms. The number of participating institutions declined from 50 to fewer than 20 in 1988. After the Philadelphia Fed took over in 1990, participation rose again; see Croushore (1993). Regarding our latest observation in 2013Q4, 42 forecasters participated in the survey.

${ }^{5}$ For the SPF forecasts of GNP/GDP we use the series DRGDP2, which we obtain from the Real-time Data Research Center of the Philadelphia Fed. This series corresponds to the median nowcast of the quarterly growth rate of real output, seasonally adjusted at annual rates (real GNP prior to 1992 and real GDP afterwards). Also note that prior to 1981Q3 the SPF asks for nominal GNP only. In this case, the nowcast for the price index of GNP is applied to obtain the implied forecast for real GNP.

${ }^{6}$ Data are obtained from BEA and the Philadelphia Fed's Real-time Data Set for Macroeconomists. First-release data: BEA's first (advance) estimate of the quarterly growth rate of real GNP/GDP (seasonally adjusted at annual rate, with real GNP prior to 1992 and real GDP for 1992-present), labeled ROUT-
} 
Nowcast errors

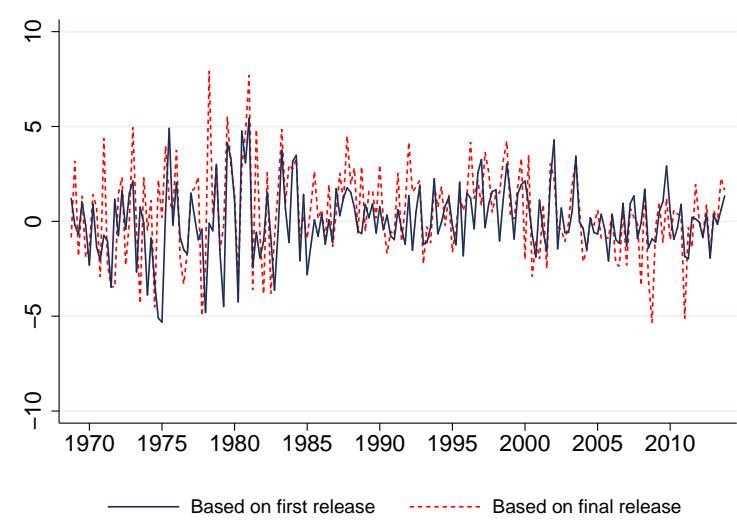

Output after nowcast error

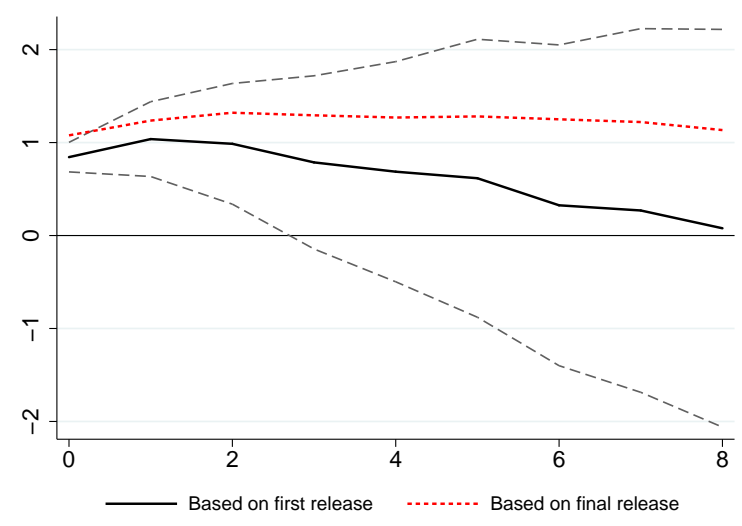

Figure 1: Nowcast error. Left panel: series based on first-release data (solid) and final-release data (dashed). Errors are measured in annualized percentage points (vertical axis). Right panel: cumulative impulse response of output growth to nowcast error based on local projections. Horizontal axis measures quarters, vertical axis measures percentage deviation of output from the average-growth path. Dashed lines indicate 90 percent confidence bounds implied by Newey-West standard errors.

available data vintage. We thereby address concerns that the assessment of nowcasts or, more generally, forecasts depends on what is being used as the "actual" or realization (see, e.g., Stark and Croushore 2002). ${ }^{7}$

\subsection{Nowcast errors}

We compute nowcast errors as the difference between actual output growth in a given quarter and the median value of the predicted value. They are shown in the left panel of Figure 1, measured in annualized percentage points. The solid and dashed lines represent results based on first-release and final-release data, respectively. Although the two series comove strongly (correlation: 0.54), there are perceptible differences. For instance, there are sizable negative errors in the second half of 2008 only for the measure based on final-release data. Presumably, at the beginning of the great recession the actual growth slowdown was larger not only relative to what professional forecasters predicted in real time, but also relative to what initial data suggested. Moreover, errors based on first-release data are shifted downwards relative to those based on final-release data, notably in the first half of

PUT. Final-release data: series GNPC96 and GDPC96 which are quarterly Gross National/Domestic Product, seasonally adjusted at annual rates, chained 2009 Dollars.

${ }^{7}$ In fact, the authors consider a set of alternative definitions of actuals and find statistically significant differences of forecast evaluations for real output. We show below, however, that our results hold independently of the choice of first- or final-release data. 
Table 1: Summary statistics nowcast errors

\begin{tabular}{llllllll} 
& & & & & \multicolumn{4}{c}{ Ljung-Box test } \\
& $\mathrm{N}$ & Mean & SD & Min & Max & Q-stat. & p-value \\
\hline & & & & & & & \\
Final-release based & 181 & $.48^{* * *}$ & 2.34 & -5.34 & 7.93 & 3.33 & .91 \\
First-release based & 181 & .05 & 1.84 & -5.31 & 5.43 & 8.66 & .37
\end{tabular}

Notes: Nowcast errors computed on the basis of final-release (top row) and first-release (bottom row) data, measured in annualized percentage points; sample: 1968Q4-2013Q4. Means are tested against zero based on a standard t-test. ' $* * *$ ' indicates significance at the $1 \%$ level. The last two columns report Q-statistics and p-values for a Ljung-Box test assessing the null hypothesis of zero autocorrelations up to 8 lags.

the sample.

This is confirmed by the summary statistics reported in Table 1: the mean of the nowcast errors is significantly positive if we consider final-release data, but not significantly different from zero in the case of first-release data. The standard error and the largest realizations of the nowcast error are also considerably larger in the case of final-release data. ${ }^{8}$ The difference is likely due to the revision process of the statistical office and particularly to benchmark revisions. We therefore rely on first-release data in our baseline VAR model in section 4, and consider final-release data in our sensitivity analysis. Finally, the last two columns of Table 1 report results of a Ljung-Box test, suggesting that there is no serial correlation in both series. Hence, in this regard nowcast errors differ considerably from forecast errors which tend to exhibit considerable persistence. ${ }^{9}$

What causes nowcast errors? Assuming that the average forecaster has a correct understanding of the economy, structural innovations that are public information should not induce systematic forecast errors. On the other hand, structural innovations that are not directly observable by market participants may generate nowcast errors. To assess this hy-

\footnotetext{
${ }^{8}$ This finding is consistent with evidence provided by Faust et al. (2005) regarding GDP announcements. For G7 countries it turns out that revisions of initial announcements are significantly positive on average in their sample period. Note, however, that the mean of final-release nowcast errors becomes insignificant once we control for productivity shocks below.

${ }^{9}$ Zarnowitz (1985) finds that serial correlation in forecast errors tends to increase with the forecasting horizon for many macroeconomic variables in the SPF. In addition, serial correlation seems to be most prevalent in inflation forecasts stimulating a large body of literature on the topic while evidence for GDP forecasts is rather mixed.
} 
pothesis, we run regressions of nowcast errors on popular (and relatively uncontroversial) series of structural innovations. Specifically, we consider monetary policy shocks identified by Romer and Romer (2004), defense spending news identified by Ramey (2014), tax shocks identified by Romer and Romer (2010), uncertainty shocks identified by Bloom (2009), and productivity shocks provided by Fernald (2012). ${ }^{10}$

In each instance, we regress nowcast errors on the contemporaneous realization of the structural shock, while also including four lags of the nowcast error in the regression model. The sample varies across regressions, since we use the longest overlapping sample in each case. Results for the impact effect are reported in Table 2. Newey-West standard errors are displayed in parentheses. The top row reports results based on the final-release data, the bottom row is based on the first-release data. We find that for monetary and fiscal policy innovations, as well as for uncertainty shocks, there is indeed no significant impact on nowcast errors, in line with the hypothesis that the effect of observable innovations on economic activity is relatively well understood by forecasters. ${ }^{11}$ Instead, productivity innovations have a significant impact. Specifically, positive productivity innovations tend to raise the nowcast error contemporaneously, that is, they tend to raise the growth of economic activity beyond the expected level.

\footnotetext{
${ }^{10}$ Following Basu et al. (2006), Fernald constructs a utilization-adjusted series of TFP at quarterly frequency. In terms of actual series we use "utilization-adjusted TFP in producing non-equipment output" (dtfp_C_util) of Fernald (2012). For the uncertainty shocks we rely on the quarterly average of the monthly series of stock-market volatility shocks identified in the baseline VAR of Bloom (2009). In the case of monetary and tax shocks we use the quarterly average of the monthly shock series (RESID) and the "sum of Deficit-Driven and Long-Run Tax Changes" (EXOGENRRATIO) of Romer and Romer (2004) and Romer and Romer (2010) respectively. The defense news identified by Ramey (2014) are the present value change in expected defense spending due to political events scaled by lagged, nominal GDP.

${ }^{11}$ Coibion and Gorodnichenko (2012b) find that mean forecast errors of inflation respond persistently to shocks. In order to resolve an apparent conflict with our results regarding the effects of policy and uncertainty shocks, we make two observations. First, we are interested in output growth rather than inflation. In a related paper, Coibion and Gorodnichenko (2012a) consider to what extent current forecast revisions predict forecast errors. In a univariate context, the contribution of forecast revisions (averages over all considered horizons) appears to be strongly significant for inflation, but barely significant in the case of output growth. Second, we focus on nowcast rather than on forecast errors. Professional forecasters tend to adjust the latter more smoothly for a number of reasons (Nordhaus 1987). This conjecture is also borne out by a result of Coibion and Gorodnichenko (2012a): while forecast revisions tend to predict forecast errors, the effect is only marginally significant for nowcast errors.
} 
Table 2: Nowcast errors and structural innovations to...

$\begin{array}{ccc}\text { Monetary } & \text { Defense } & \text { Taxes } \\ \text { Policy } & \text { Spending } & \end{array}$

1969:1-1996:4 1968:4-2013:4 1968:4-2007:4 1963:3-2008:2 1968:4-2009:3

$\begin{array}{lccccc}\text { Nowcast Error } & 1.675 & 0.149 & -.085 & .424 & .476 * * * \\ \text { (Final release) } & (1.010) & (0.127) & (1.174) & (.439) & (.050) \\ \text { Nowcast Error } & 1.581 & 0.127 & -.740 & .088 & .141^{* * *} \\ \text { (First release) } & (.976) & (.102) & (.971) & (.260) & (.045)\end{array}$

Notes: Impact effect on nowcast error obtained from regressing the nowcast error on the time series for the structural innovations to monetary policy, fiscal policy (government spending and taxes), uncertainty, and productivity. The regression includes four lags of the nowcast error. Newey-West standard errors robust for autocorrelation up to four lags are reported in parentheses; time series of structural innovations to monetary policy, defense spending, taxes, uncertainty, and productivity provided by Romer and Romer (2004), Ramey (2014), Romer and Romer (2010), Bloom (2009), and Fernald (2012) respectively.

\subsection{Nowcast errors and economic activity}

Nowcast errors are positive surprises regarding current activity. They are also positively correlated with output growth. ${ }^{12}$ To explore systematically how current nowcast errors relate to economic activity, we estimate the dynamic relationship on the basis of local projections (see Jordà 2005). In particular, we relate current and future output growth to current nowcast errors. ${ }^{13}$

The right panel of Figure 1 shows the cumulative impulse response of output growth to a nowcast error. The horizontal axis measures quarters, the vertical axis percentage deviation of output from the constant-growth path. Dashed lines indicate 90 percent confidence bounds implied by Newey-West standard errors. We find that nowcast errors predict a strong, mildly hump-shaped increase of economic activity. The effect is stronger for our measure based on final-release data, yet differences are moderate relative to the one based

\footnotetext{
${ }^{12}$ The correlation between GDP growth (final-release data) and the nowcast error is .73 and .47 for the final-release and first-release measure respectively.

${ }^{13}$ To capture potential serial correlation, we apply Newey-West standard errors. The error structure is assumed to be possibly heteroskedastic and autocorrelated up to lag 4. We also include four lags of GDP growth in the regression.
} 
on first-release data. The finding that (reduced-form) nowcast errors predict future activity to increase is noteworthy in light of our estimates regarding the effects of optimism shocks documented in Section 4 below. Before discussing our empirical framework, we provide its theoretical rationale in the following section.

\section{Optimism shocks: Theory}

In this section we put forward a model which allows us to formally define optimism shocks, discuss conditions under which they may affect economic activity and, importantly, clarify issues pertaining to identification. Importantly, the model captures in a stylized way the informational friction, which gives rise to nowcast errors. Lorenzoni (2009) and Coibion and Gorodnichenko (2012b) find that models of information rigidities in general, and of noisy information in particular, are successful in predicting empirical regularities of survey data on expectations. Our model thus builds on the noisy and dispersed information model of Lorenzoni (2009), a key feature of which is that agents do not observe current output. As our goal is to derive robust qualitative predictions, we simplify the original model, notably by assuming predetermined rather than staggered prices. As a result, it is possible to solve an approximate model in closed form.

\subsection{Setup and timing}

There is a continuum of islands (or locations), indexed by $l \in[0,1]$, each populated by a representative household and a unit mass of producers, indexed by $j \in[0,1]$. Each household buys from a subset of all islands, chosen randomly in each period. Specifically, it buys from all producers on $n$ islands included in the set $\mathcal{B}_{l, t}$, with $1<n<\infty$. ${ }^{14}$ Households have an infinite planning horizon. Producers produce differentiated goods on the basis of island-specific productivity, which is determined by a permanent, economy-wide component and a temporary, idiosyncratic component. Both components are stochastic. Financial markets are complete such that, assuming identical initial positions, wealth levels of households are equalized at the beginning of each period.

The timing of events is as follows: Each period consists of three stages. During stage one of period $t$, information about all variables of period $t-1$ is released. Subsequently, nominal

\footnotetext{
${ }^{14}$ This setup ensures that households cannot infer aggregate productivity exactly from observed prices. At the same time, individual producers have no impact on the price of households' consumption baskets.
} 
wages are determined. Finally, the central bank sets the interest rate based on expected inflation.

Shocks realize during the second stage. We distinguish between shocks which are directly observable and shocks which are not. Optimism and productivity shocks fall in the latter category. In particular, information about idiosyncratic productivity is private to each producer. Additionally, all agents observe a signal about average productivity. While the signal is unbiased, it contains an i.i.d. zero-mean component: the optimism shock. In terms of observable shocks, we allow for monetary policy shocks. Yet, rather than being interested in the effects of monetary policy shocks per se, we merely aim at contrasting the effects of observable shocks on nowcast errors to those of non-observable shocks. Given these information sets, producers set prices.

During the third and final stage, households split up. Workers work for all firms on their island, while consumers allocate their expenditures across differentiated goods based on public information, including the signal, and information contained in the prices of the goods in their consumption bundle. Because the common productivity component is permanent and households' wealth and information is equalized in the next period, agents expect the economy to settle on a new steady state from period $t+1$ onwards.

\subsection{Households}

A representative household on island $l$ maximizes lifetime utility given by

$$
U_{l, t}=E_{l, t} \sum_{k=t}^{\infty} \beta^{k-t} \ln C_{l, k}-\frac{L_{l, k}^{1+\varphi}}{1+\varphi} \quad \varphi \geq 0, \quad 0<\beta<1,
$$

with $E_{l, t}$ being the expectation operator based on household l's information set at the time of its consumption decision (see below). $C_{l, t}$ denotes the consumption basket of household $l$, while $L_{l, t}$ is its labor supply. The flow budget constraint is given by

$E_{t} \varrho_{l, t, t+1} \Theta_{l, t}+B_{l, t}+\sum_{m \in \mathcal{B}_{l, t}} \int_{0}^{1} P_{j, m, l, t} C_{j, m, l, t} d j \leq \int_{0}^{1} \Pi_{j, l, t} d j+W_{l, t} L_{l, t}+\Theta_{l, t-1}+\left(1+r_{t-1}\right) B_{l, t-1}$,

where $C_{j, m, l, t}$ denotes the amount bought by household $l$ from producer $j$ on island $m$ and $P_{j, m, l, t}$ is the price for one unit of $C_{j, m, l, t} . \Pi_{j, l, t}$ are profits of firm $j$ on island $l$ and $\varrho_{l, t, t+1}$ is household $l$ 's stochastic discount factor between $t$ and $t+1$. At the beginning of the period, the household receives a payoff $\Theta_{l, t-1}$ from its portfolio of state-contingent 
securities, purchased in the previous period. $B_{l, t}$ are state non-contingent bonds paying an interest rate of $r_{t}$. A complete set of state-contingent securities is traded at the beginning of the period, while state non-contingent bonds can be traded via the central bank throughout the entire period. The interest rate of the non-contingent bond is set by the central bank. All financial assets are in zero net supply. The bundle $C_{l, t}$ of goods purchased by household $l$ consists of goods sold in a subset of all islands in the economy

$$
C_{l, t}=\left(\frac{1}{n} \sum_{m \in \mathcal{B}_{l, t}} \int_{0}^{1} C_{j, m, l, t}^{\frac{\gamma-1}{\gamma}} d j\right)^{\frac{\gamma}{\gamma-1}} \quad \gamma>1 .
$$

While each household purchases a different random set of goods, we assume that the number $n$ of islands visited is the same for all households. The price index of household $l$ is

$$
P_{l, t}=\left(\frac{1}{n} \sum_{m \in \mathcal{B}_{l, t}} \int_{0}^{1} P_{j, m, l, t}^{1-\gamma} d j\right)^{\frac{1}{1-\gamma}}
$$

\subsection{Producers and monetary policy}

The central bank follows a standard Taylor rule but sets the net interest rate $r_{t}$ before observing prices, that is during stage one of period $t$ :

$$
r_{t}=\psi E_{c b, t} \pi_{t}+\theta_{t} \quad \psi>1
$$

where $\pi_{t}$ is economy-wide net inflation, calculated on the basis of all goods sold in the economy. The expectation operator $E_{c b, t}$ conditions on the information set of the central bank, which consists of information from period $t-1$ only. ${ }^{15} \theta_{t}$ is a monetary policy shock that is observable by producers and households alike.

Producer $j$ on island $l$ produces according to the following production function

$$
Y_{j, l, t}=A_{j, l, t} L_{j, l, t}^{\alpha} \quad 0<\alpha<1
$$

featuring labor supplied by the local household as the sole input. $A_{j, l, t}=A_{l, t}$ denotes the

\footnotetext{
${ }^{15}$ Pre-set prices and interest rates allow us to discard the noisy signals about quantities and inflation observed by producers and the central bank in Lorenzoni (2009), simplifying the signal-extraction setup without changing the qualitative predictions of the model. Pre-set wages, on the other hand, guarantee determinacy of the price level. They do not affect output dynamics after optimism and productivity shocks, because good prices may still adjust.
} 
productivity level of producer $j$, which is the same for all producers on island $l$. During stage two, the producer sets her optimal price for the current period. Given prices, the level of production is determined by demand during stage three.

\subsection{Productivity and signal}

Log-productivity on each island, denoted by small-case letters, is the sum of an aggregate and an island-specific idiosyncratic component

$$
a_{l, t}=x_{t}+\eta_{l, t}
$$

where $\eta_{l, t}$ is an i.i.d. shock with variance $\sigma_{\eta}^{2}$ and mean zero. It aggregates to zero across all islands. The aggregate component $x_{t}$ follows a random walk

$$
\Delta x_{t}=\varepsilon_{t}
$$

The i.i.d. productivity shock $\varepsilon_{t}$ has variance $\sigma_{\varepsilon}^{2}$ and mean zero. During stage two of each period, agents observe a public signal about $x_{t}$. This signal takes the form

$$
s_{t}=\varepsilon_{t}+e_{t}
$$

where $e_{t}$ is an i.i.d. optimism shock with variance $\sigma_{e}^{2}$ and mean zero. Producers also observe their own productivity. Hence, their expectations of $\Delta x_{t}$ are

$$
E_{j, l, t} \Delta x_{t}=\rho_{x}^{p} s_{t}+\delta_{x}^{p}\left(a_{j, l, t}-x_{t-1}\right)
$$

with $E_{j, l, t}$ being the expectation of producer $j$ on island $l$ when setting prices (stage two). The coefficients $\rho_{x}^{p}$ and $\delta_{x}^{p}$ are the same for all producers, where these and the following $\rho$ and $\delta$-coefficients are functions of the structural parameters which capture the informational friction. They are non-negative and smaller than unity (see Appendix A). Finally, while shopping during stage three consumers observe a set of prices. Given that they have also observed the signal, they can infer the productivity level of each producer in their sample. Consumers' expectations are thus given by

$$
E_{l, t} \Delta x_{t}=\rho_{x}^{h} s_{t}+\delta_{x}^{h} \tilde{a}_{l, t},
$$


where $\tilde{a}_{l, t}$ is the average over the realizations of $a_{m, t}-x_{t-1}$ for each island $m$ in household l's sample. $\rho_{x}^{h}$ and $\delta_{x}^{h}$ are equal across households. The model nests the case of complete information about all relevant variables for households and producers if $\sigma_{e}^{2}=0$. If $\sigma_{e}^{2}>0$, producers will set prices based on potentially overly optimistic or pessimistic expectations of productivity. Consumers also have complete information if $n \rightarrow \infty$.

\subsection{Market clearing}

Good and labor markets clear in each period:

$$
\int_{0}^{1} C_{j, m, l, t} d l=Y_{j, m, t} \forall j, m \quad L_{l, t}=\int_{0}^{1} L_{j, l, t} d j \quad \forall l,
$$

where $C_{j, m, l, t}=0$ if household $l$ does not visit island $m$. The asset market clears by Walras' law.

\subsection{Results}

We derive a solution of the model based on a linear approximation to the equilibrium conditions around the symmetric steady state, see Appendix A for details. We obtain the following propositions, for which we provide proofs in Appendix B.

Proposition 1 A positive optimism shock ( $\left.e_{t}>0\right)$, a positive productivity shock $\left(\varepsilon_{t}>0\right)$, and a negative monetary policy shock $\left(\theta_{t}<0\right)$ raise output. Formally, we have

$$
y_{t}=x_{t-1}+\underbrace{\rho_{x}^{h}(1-\Omega)}_{>0} e_{t}+\underbrace{\left[\left(\delta_{x}^{h}+\rho_{x}^{h}\right)(1-\Omega)+\Omega\right]}_{>0}] \underbrace{}_{t}-\underbrace{\frac{\alpha}{\alpha+\psi(1-\alpha)}}_{<0} \theta_{t},
$$

with $0<\Omega=\frac{n-\delta_{x}^{h}(1-\alpha)\left[(n-1) \delta_{x}^{p}+1\right]}{n \alpha+(1-\alpha)\left\{\left(1-\delta_{x}^{h}\right)\left[1+\delta_{x}^{p}(n-1)\right]+(n-1) \gamma\left(1-\delta_{x}^{p}\right)\right\}}<1$.

Proposition 2 A positive optimism shock induces a negative nowcast error, while a positive productivity shock induces a positive nowcast error. This holds for nowcast errors of producers and households alike. Formally,

$$
y_{t}-E_{k, t} y_{t}=\underbrace{-\rho_{x}^{k}\left[\delta_{x}^{h}(1-\Omega)+\Omega\right]}_{<0} e_{t}+\underbrace{\left[\delta_{x}^{h}(1-\Omega)+\Omega\right]\left(1-\delta_{x}^{k}-\rho_{x}^{k}\right)}_{>0} \varepsilon_{t},
$$

with $E_{k, t}$ standing for either $E_{j, l, t}$ or $E_{l, t}$, and $\rho^{k}, \delta^{k}$ correspondingly for $\rho^{p}, \delta^{p}$ or $\rho^{h}, \delta^{h}$. 
Hence, productivity and optimism shocks raise actual output, but also lead to output misperceptions. Consider first the optimism shock. Producers expect aggregate productivity to be high - resulting in higher demand - but also observe that their own productivity is unchanged, which they attribute to a negative realization of the idiosyncratic productivity component. Consequently, they raise prices above what they expect the average price level to be. However, due to strategic complementarities in price stetting, the deviation from the expected average price level is subdued. Consumers, in turn, observe higher prices. They too attribute this increase to adverse productivity shocks suffered by those particular firms from which they buy. This allows households to entertain the notion of higher aggregate productivity and future income. Because the observed price increase is muted relative to the expected long-run price level, expenditure and, consequently, economic activity expand. ${ }^{16}$ Yet as each producer and each household considers itself unlucky relative to its peers, current output is actually lower than expected: a negative nowcast error obtains. After a productivity shock, on the other hand, producers do not fully trust the signal about the aggregate component and attribute some of the increased productivity to idiosyncratic factors. They therefore lower prices below what they expect the average price level to be. Consumers expect higher income and raise consumption. However, both producers and their customers expect other producers to set higher prices and consequently underestimate actual output. A positive nowcast error obtains.

Furthermore, observe that monetary policy shocks have no impact on nowcast errors. More generally, any other shock that enters the information set of households and producers will not generate nowcast errors, as both are aware of the economic environment and hence the effect of shocks. Misperceptions about economic activity thus arise only after imperfectly observed shocks, such as innovations to productivity, or incorrect signals regarding productivity.

\subsection{VAR representation}

In addition to clarifying the nature of optimism shocks, the model allows us to address concerns about whether optimism shocks can be uncovered at all on the basis of an estimated VAR model. In this regard, the set of actual time series used in the estimation is crucial. Noting that we estimate our VAR in Section 4 on time series for nowcast errors,

\footnotetext{
${ }^{16}$ As pointed out by Lorenzoni (2009), the optimism shock provides a possible microfoundation for the traditional concept of a demand shock: agents are too optimistic about economic fundamentals, resulting in unusually high demand.
} 
labor productivity, and hours worked, that is, on the following vector

$$
\tilde{Y}_{t}^{\prime}=\left[\begin{array}{lll}
\Delta y_{t}-E_{k, t} \Delta y_{t} & \Delta\left(y_{t}-l_{t}\right) & l_{t}
\end{array}\right]
$$

we obtain the following proposition.

Proposition 3 Given $\tilde{Y}_{t}$, the dynamics of the model can be represented by a $\operatorname{VAR}(1)$ :

$$
\tilde{Y}_{t}=A \tilde{Y}_{t-1}+B \tilde{V}_{t}
$$

where

$$
\tilde{V}_{t}^{\prime}=\left[\begin{array}{lll}
\varepsilon_{t} & e_{t} & \theta_{t}
\end{array}\right]
$$

and the matrices $A$ and $B$ are given in the proof.

Intuitively, we are able to cast the model dynamics in VAR form because we rely on variables that are not contemporaneously observed in the model. If, instead, one were to restrict the VAR to contain variables observed by agents in real time, the model would generally not be invertible. Proposition 3 is thus consistent with the result of Blanchard et al. (2013), according to which optimism shocks cannot be recovered from actual time-series data by an econometrician who has no informational advantage over market participants. ${ }^{17}$ Yet as documented in Section 2, actual nowcast errors regarding output growth can be sizeable. To the extent that they can be measured ex post, they allow us to identify optimism shocks.

Finally, the model also provides us with specific identification restrictions, which we impose on the VAR model below. Given matrices $A$ and $B$, we obtain the following corollary.

Corollary 1 Monetary policy shocks have no impact on the nowcast error, neither in the short nor the long run. Furthermore, optimism shocks do not alter labor productivity in the long run.

\footnotetext{
${ }^{17}$ Additionally, Blanchard et al. (2013) show within a representative agent model that it is impossible to identify noise shocks precisely in the presence of an aggregate temporary technology shock. Our model, instead, allows for firm heterogeneity as in Lorenzoni (2009) and temporary technology shocks are assumed to aggregate to zero over all firms. Agents and econometricians can thus identify noise shocks ex post as information about past aggregate variables becomes available. As argued by Lorenzoni (2009), assuming firm-specific technology shocks permits to account for the observation that firm-level volatility exceeds aggregate volatility considerably.
} 


\section{Optimism shocks: Evidence}

We are now in a position to identify the effects of optimism shocks in actual time-series data and to quantify their contribution to U.S. short-run fluctuations. We do so within an estimated VAR model which includes - as the key to our identification strategy - a time series of nowcast errors. As it represents an informational advantage over market participants it allows us to tell optimism and productivity shocks apart. We employ alternative identification strategies to validate that our results are robust. We combine short and long run restrictions as, for instance, in Galí (1999). In addition, we rely on sign restrictions as proposed by Uhlig (2005). ${ }^{18}$ Before providing further details, we briefly describe our VAR setup in general terms.

\subsection{VAR specification}

Our VAR model includes three variables. Under the baseline specification we include the nowcast error computed on the basis of first-release data, the growth rate of labor productivity, and a measure of economic activity. ${ }^{19}$ Regarding the latter we either consider hours worked or output. Formally, with vector $\tilde{Y}_{t}$ containing these variables from top to bottom, the VAR model is given in reduced form by the following expression:

$$
\tilde{Y}_{t}=\sum_{i=1}^{L} A_{i} \tilde{Y}_{t-i}+\nu_{t}
$$

Here $L$ is the number of lags and $\nu_{t}$ is a vector of potentially mutually correlated innovations of which $\Omega=E \nu \nu^{\prime}$ is the covariance matrix. We also include a constant in the VAR model. ${ }^{20}$

We estimate the model under our baseline specification on quarterly data covering the period 1983Q1-2013Q4. While our measure of nowcast errors is available since the late 1960s (see Section 2), we disregard observations prior to 1983, because the U.S. business cycle has been subject to considerable changes in the early 1980s, possibly because of a

\footnotetext{
${ }^{18}$ Applications of sign restrictions to different settings include Peersman (2005) and Enders et al. (2011).

${ }^{19}$ Labor productivity is measured by (the first difference of the natural logarithm of) output per hour of all persons in the nonfarm business sector and hours worked is the natural logarithm of the corresponding hours. Both series are obtained from the Bureau of Economic Analysis. Results are robust, however, once we measure labor productivity as output per person and hours as employment, both obtained from the Bureau of Labor Statistics.

${ }^{20}$ Below, we consider alternative trend specifications to address the potential non-stationarity of the time series for hours worked.
} 
change in the conduct of monetary policy (Clarida et al. 2000; McConnell and Perez-Quiros 2000). Below, we also report results of a sensitivity analysis exploring the robustness of our results with respect to estimating the model on the full sample.

Regarding the number of lags $L$, we account for concerns about a lag-truncation bias. As argued by Chari et al. (2008), it is particularly severe in the case long-run restrictions are imposed on the VAR model. De Graeve and Westermark (2013) perform Monte Carlo experiments and find that raising the number of lags may be a viable strategy to reduce the severity of the problem. Hence, for our baseline specification we set $L=8$.

\subsection{Identification}

We aim to identify structural shocks contained in the vector, $\epsilon_{t}$, with $\nu_{t}=B \epsilon_{t}$ and $E \epsilon \epsilon^{\prime}=I$. Given estimates for $\Omega$ and the $A_{i}$ matrices, we consider alternative strategies to identify $B$. Throughout, without loss of generality, we assume that $\epsilon_{t}$ contains from top to bottom the technology shock, the optimism shock, and a third shock to which we do not attach any structural interpretation. For lack of a better term we refer to this shock as "rest shock". In what follows we consider three alternative identification schemes.

Throughout, we assume, in line with the model developed in the previous section (Corollary 1), that nowcast errors are contemporaneously affected only by technology and optimism shocks. Moreover, this assumption is also consistent with the evidence provided in Section 2. Formally, we restrict the upper-left element of the impact matrix to be equal to zero:

$$
B=\left[\begin{array}{lll}
* & * & 0 \\
* & * & * \\
* & * & *
\end{array}\right]
$$

\subsubsection{Baseline}

Under our baseline identification strategy we impose long-run restrictions in addition to the short-run restriction (4.2). As in Galí (1999) we assume that only technology shocks impact labor productivity in the long run. We also follow Galí (1999) and include hours worked as a measure for economic activity in our VAR model under the baseline identification

scheme. We recover the response of output from the joint dynamics of hours and labor productivity (output/hour).

Formally, we impose two zero restrictions on the matrix $A_{0}$ which governs the long-run 
effect of the shocks:

$$
A_{0} \equiv\left(I-\sum_{i=1}^{L} A_{i}\right)^{-1} B=\left[\begin{array}{lll}
* & * & * \\
* & 0 & 0 \\
* & * & *
\end{array}\right]
$$

\subsubsection{Alternative long-run restriction}

For our second identification strategy, we keep the impact matrix $B$ restricted as in (4.2), but assume for the long-run matrix

$$
A_{0}=\left[\begin{array}{ccc}
* & * & 0 \\
* & 0 & * \\
* & * & *
\end{array}\right]
$$

Hence, in contrast to the baseline identification scheme (4.3), (4.4) allows labor productivity to be affected in the long-run by shocks other than technology shocks. This is appealing to the extent that technology shocks may be anticipated and, at the same time, may have permanent effects. Under our baseline identification scheme this possibility is ruled out, because anticipated technology shocks would not impact the nowcast error and, hence, would be constrained not to impact labor productivity in the long run. ${ }^{21}$

\subsubsection{Sign restrictions}

Our third identification strategy relies on sign restrictions, in addition to the zero restriction given in (4.2). Specifically, we restrict the set of possible impact matrices $B$ to those for which the impulse responses to the shocks of interest conform with theory-both in terms of timing and sign of the impulse responses. While our restrictions are in line with the predictions of the model developed in Section 3, they are likely to be satisfied across a wide range of models.

In particular, we assume that positive optimism shocks increase economic activity, but less than contemporaneously expected: they are restricted to induce a negative nowcast error. Positive technology shocks, on the other hand, are assumed to induce a positive nowast error, as they raise economic activity beyond the expected level. When imposing

\footnotetext{
${ }^{21} \mathrm{~A}$ possible concern with (4.4) is that a restriction on the long-run response of the nowcast error may have little bite. After all, the nowcast error is a stationary variable and will thus not wander off too far in response to shocks even if unrestricted. However, Monte Carlo experiments based on the model 3 show that the VAR is able to capture the impulse response functions in qualitatively satisfactory way, if restrictions (4.2) and (4.4) are imposed. Results are available on request.
} 
Table 3: Joint sign and zero restrictions

\begin{tabular}{l|ccc}
\hline Sariable & Technology & Optimism & Rest \\
\hline Nowcast error & $\uparrow$ & $\downarrow$ & 0 \\
Labor productivity & $*$ & $*$ & $*$ \\
Output & $\uparrow$ & $\uparrow$ & $*$ \\
\hline \hline
\end{tabular}

Notes: $\uparrow(\downarrow)$ indicates that shocks are restricted to impact variables non-negatively (non-positively); 0 indicates a zero restriction, $*$ denotes a non-restricted response.

sign restrictions, we include output in the VAR model rather than hours worked, as the response of hours worked to technology shocks is subject to a considerable debate (see Galí 1999, Francis and Ramey 2005, and Chari et al. 2008, among others). Again, the response of hours can be backed out from the responses of labor productivity and output. Table 3 summarizes the restrictions which we impose on matrix $B$.

There are many different matrices $B$ which satisfy these restrictions. We therefore do not obtain exact identification. To acknowledge this point, we follow the literature and implement sign restrictions within a Bayesian context. Specifically, we estimate a Bayesian VAR (BVAR) while entertaining a Normal-Wishart prior. We impose zero and sign restrictions jointly following the procedure proposed in Balleer and Enders (2013). We draw from the unrestricted posterior distribution of the BVAR parameters and consider all possible matrices $B$ that fulfill the sign restrictions in Table $3 .^{22}$ Importantly, this procedure considers the entire space of possible rotations for a given zero restriction, placing equal weights on all admissible rotations that are associated with a specific draw from the posterior distribution. We thereby avoid imposing additional and unintended sign restrictions, an issue highlighted by Arias et al. (2014). ${ }^{23}$

\footnotetext{
${ }^{22}$ More specifically, we start with a lower-triangular Cholesky decomposition of the estimated variancecovariance matrix $\Omega$. The resulting Cholesky factor features the zero in matrix $B$ in equation (4.2). Using the appropriate Givens-matrices, we first rotate the three column vectors around the $z$-axis on 100 gridpoints. We then move one gridpoint (out of 100) on a rotation around the $x$-axis, and conduct another full rotation around the $z$-axis, and so forth. This procedure ensures that we search the entire admissible rotation space that satisfies the zero restriction in (4.2). For each gridpoint, we check whether the resulting candidate matrix $B$ (or a version in which the first and the second columns are switched, allowing an alternative ordering of the optimism and technology shocks) fulfills the sign restrictions. If it does, we keep the draw. We repeat the whole procedure for 1000 draws from the unrestricted posterior distribution of the structural parameters of the BVAR and plot intervals that cover one standard deviations of all collected draws.

${ }^{23}$ These authors develop an alternative method by drawing from all possible rotation matrices while
} 
Technology shock
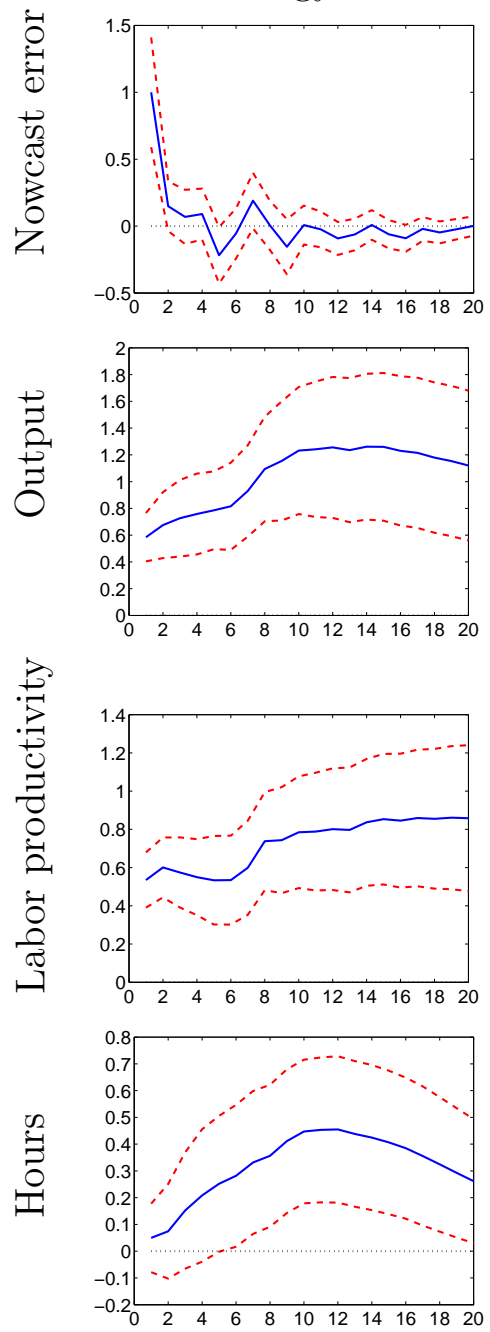

Optimism shock
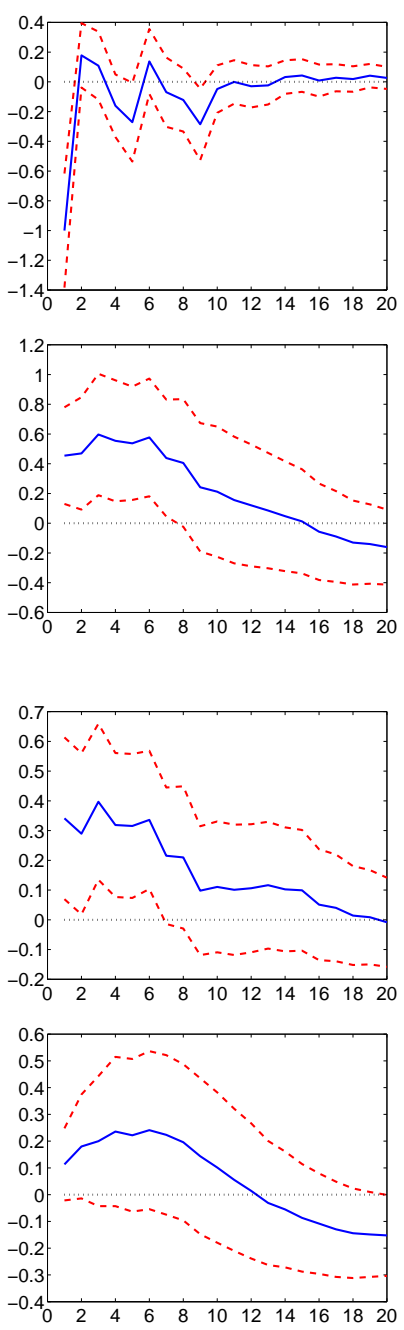

Rest shock
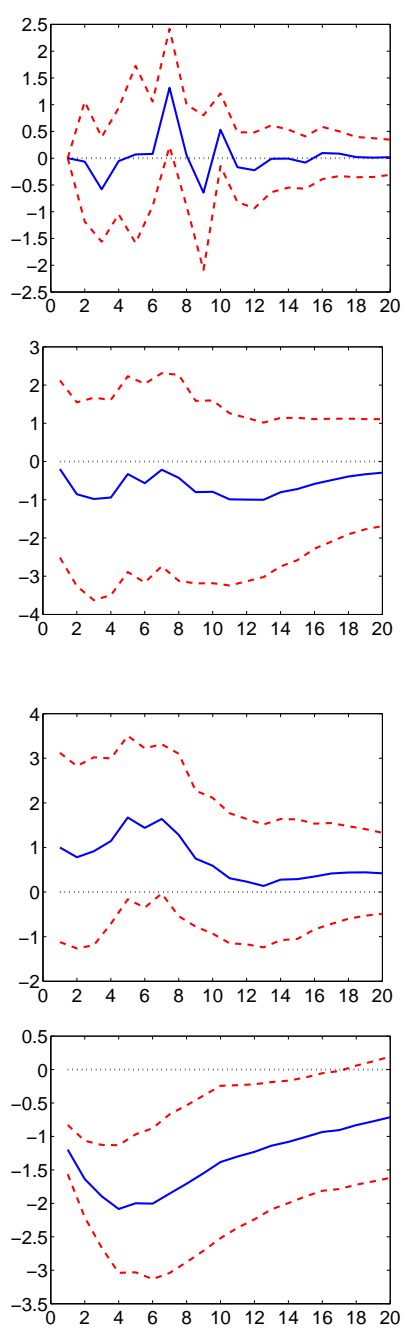

Figure 2: Impulse responses to identified shocks under baseline identification. Notes: solid lines indicate point estimates, dashed lines 90 percent confidence bounds obtained by bootstrap sampling (1000 repetitions). Horizontal axes measure quarters. Vertical axes: percentage points in the case of the nowcast error, percent otherwise.

\subsection{Results}

We compute impulse response functions on the basis of the estimated model and display results for the baseline identification scheme in Figure 2. The columns (from left to right) display the responses to a technology shock, an optimism shock, and the third shock. Solid lines represent the point estimate, while dashed lines indicate 90 percent confidence bounds

ensuring that the admissible rotations obtain equal weights. We leave a systematic comparison of the two approaches to future research. 
obtained by boostrap sampling. The rows display the responses of the nowcast error, output (implied by those of labor productivity and hours), labor productivity, and hours, respectively. In each case, horizontal axes measure time in quarters, while vertical axes measure percentage points in the case of the nowcast error and percentage deviations from the pre-shock level otherwise. To facilitate the comparison of productivity and optimism shocks, we consider in each case a shock which triggers an increase of output and normalize its size such that it induces a nowcast error equal to 1 percentage point (annualized) in absolute value. The size of the rest shock is normalized to a 1 percent (annualized) increase in labor productivity.

A first noteworthy result is the joint responses of the nowcast error and output to both structural shocks. While output rises in each instance by construction, technology shocks induce a positive response of the nowcast error, while optimism shocks trigger a negative response. This finding is in line with the prediction of the model developed in Section 3 above, even though the response of the nowcast error to both shocks has been left unrestricted (in the baseline identification). More generally, the finding that optimism shocks induce a negative co-movement of the nowcast error and output is remarkable because the unconditional co-movement of both series is positive, as established in Section 2. In our view, the result that the co-movement changes from unconditionally positive to negative conditional on optimism shocks lends additional support to our identification strategy.

The response of the nowcast error is short-lived, while the response of output to both shocks is sizeable and persistent. Also the impact response of output is comparable for both shocks. Output rises by about 0.5 percent. However, the dynamic adjustment to both shocks differs considerably. Output continues to rise after a technology shock, reaching a peak response after about 2.5 years (1.2 percent). It reverts to trend only very gradually. The peak response of output to an optimism shock, instead, is reached after three quarters (0.6 percent). The shock ceases to have a significant output effect after about 6-8 quarters. The third row shows the response of labor productivity. It increases in response to a technology shock on impact, but also in the long run. Labor productivity also increases in response to an optimism shock. ${ }^{24}$ Note that optimism shocks are not allowed to impact labor productivity in the long run under our identification scheme. The responses of hours are shown in the last row. Initially, they are somewhat weaker in the case of technology shocks and somewhat stronger in the case of optimism shocks, reflecting the differential

\footnotetext{
${ }^{24}$ This finding conflicts with the prediction of the of the model developed in Section 3 above. However, the evidence may rationalized through frictions which give rise to labor hoarding.
} 
Nowcast error restricted in LR

Technology shock
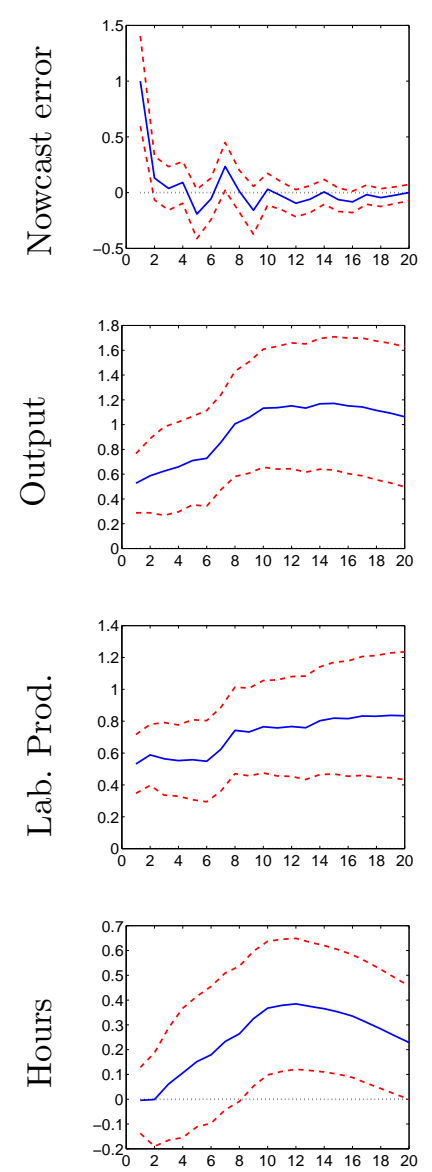

Optimism shock
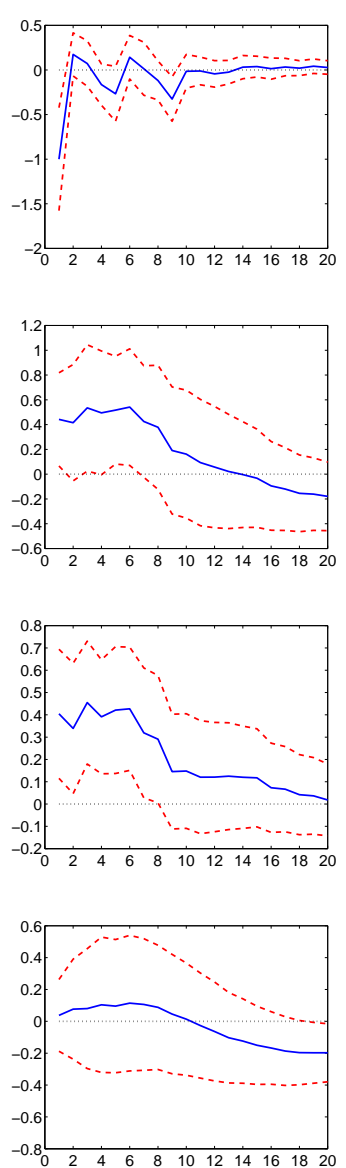

Sign restrictions

Technology shock

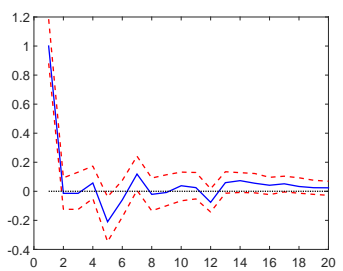

Optimism shock
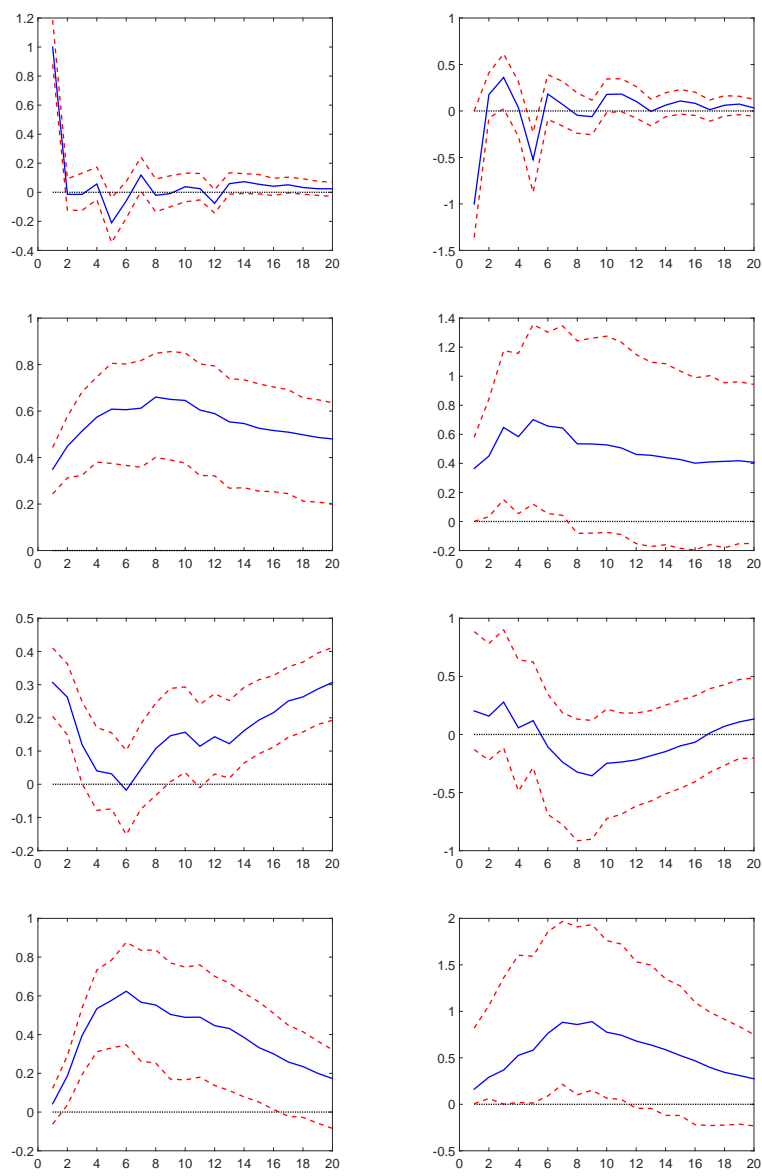

Figure 3: Impulse responses to productivity and optimism shock: alternative identification schemes. Notes: left panel shows results for alternative long-run restriction; right panel shows results for identification based on sign restrictions. For the latter, we report the median response and the 16 and $84 \%$ quantiles. (see Section 4.1 and Figure 2 for further details).

effect of these shocks on labor productivity. In the long run hours are back to the pre-shock level.

We find that our main results carry over to alternative identification schemes. The left panel of Figure 3 shows results obtained under the alternative identification schemes for which we allow the "rest" schock to impact labor productivity in the long run, but not the nowcast error. The right panel of the same figure shocks results for the identification scheme based on sign restrictions. In both panels the left column shows the impulse response to 
a technology shock, while the right column shows the impulse response to an optimism shock. Overall, results are very similar to those obtained for the baseline identification scheme - not only qualitatively, but also quantitatively (see Figure 2). Of course, under the sign restriction scheme, we restrict the sign of the nowcast error, as well as that of output. Still, we find that the dynamic adjustment after technology and optimism shocks resembles those obtained under the two other identifications schemes very closely. These schemes leave the sign of the response of the nowcast error and output unrestricted.

In order to contrast the transmission of optimism shocks to that of technology shocks it is of interest to investigate their effects on variables other than those included in the baseline model. To estimate the impulse responses of these variables while economizing on the degrees of freedom, we rotate additional variables one-by-one into our VAR model, replacing the time series for hours worked. Figure 4 displays results for additional variables of particular interest, obtained under the baseline identification scheme (left) and identification based on sign restrictions (right). ${ }^{25}$ The first two rows show the responses of consumption and investment respectively. ${ }^{26}$ Applying the same normalization as above, we find that technology and optimism shocks raise consumption and investment, although the effect is stronger and more persistent in the case of technology shocks.

The third row of Figure 4 shows the response of core CPI inflation. ${ }^{27}$ We find that optimism shocks induce a significant rise of inflation. Optimism shocks thus share important features of what has been traditionally referred to as a demand shock. Technology shocks are also inflationary, but the effect is not significant. The fourth row of Figure 4 shows the response of the stock prices in real terms. ${ }^{28}$ The increase strongly in response to technology shocks, but also in response to optimism shocks.

Finally, in the last row, we show the response of a direct measure of total factor productivity. Investigating its response to technology shocks helps to assess the plausibility of our identification schemes. The time series for total factor productivity is obtained from Fernald (2012), see Section 2. The impulse responses show a strong increase of TFP to the technology shock, but no significant reaction to optimism shocks in the long run.

Overall, we find plausible results regarding the effects of optimism shocks and thus turn to

\footnotetext{
${ }^{25}$ Results for the alternative identification scheme based on long-run restrictions are very much in line with those shown in Figure 4.

${ }^{26}$ Consumption is measured by real personal consumption expenditures and investment by real gross private domestic investment, both from the Bureau of Economic Analysis.

${ }^{27}$ Inflation is computed for the consumer price index provided by the Bureau of Labor Statistics (Consumer Price Index for Urban Wage Earners and Clerical Workers: All Items Less Energy).

${ }^{28}$ Here we consider the mid-quarter value of the S\&P 500 index, deflated by the CPI index.
} 
Baseline identification
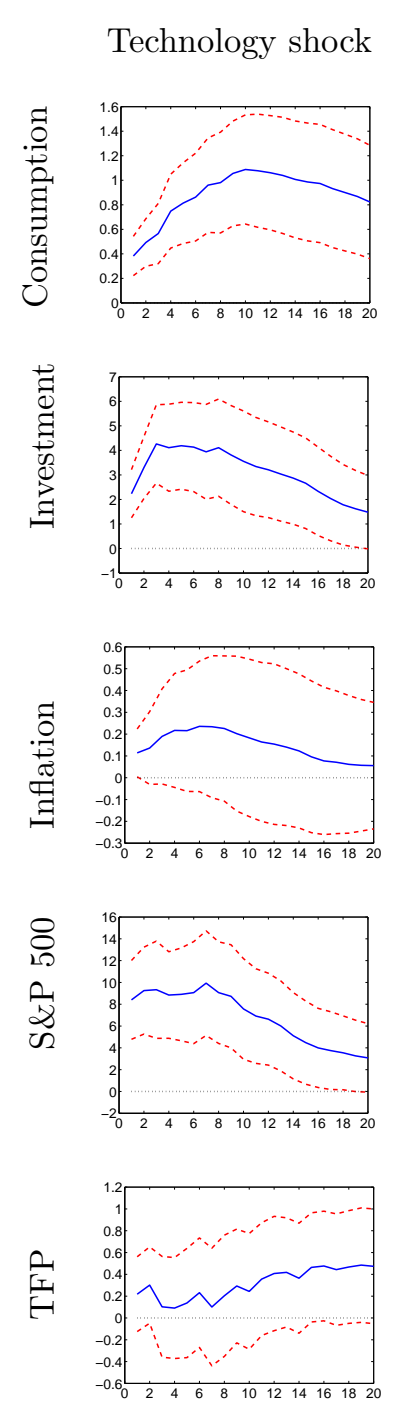
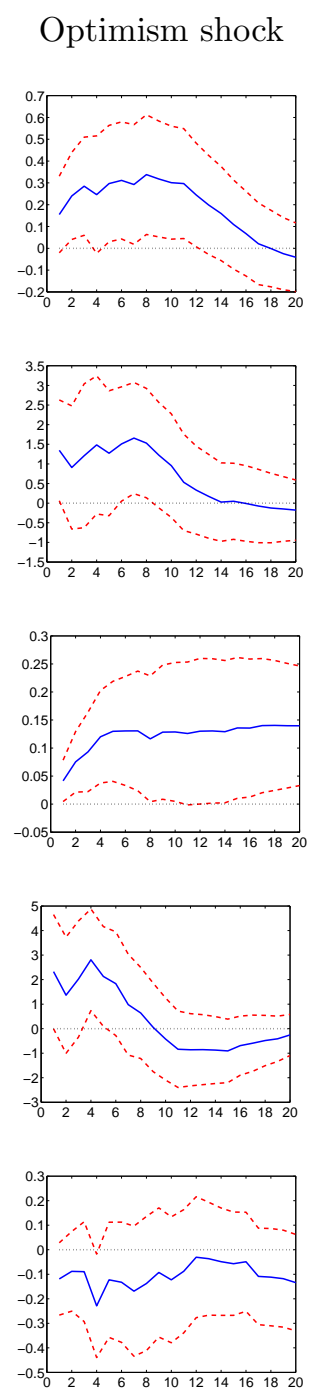

Sign restrictions
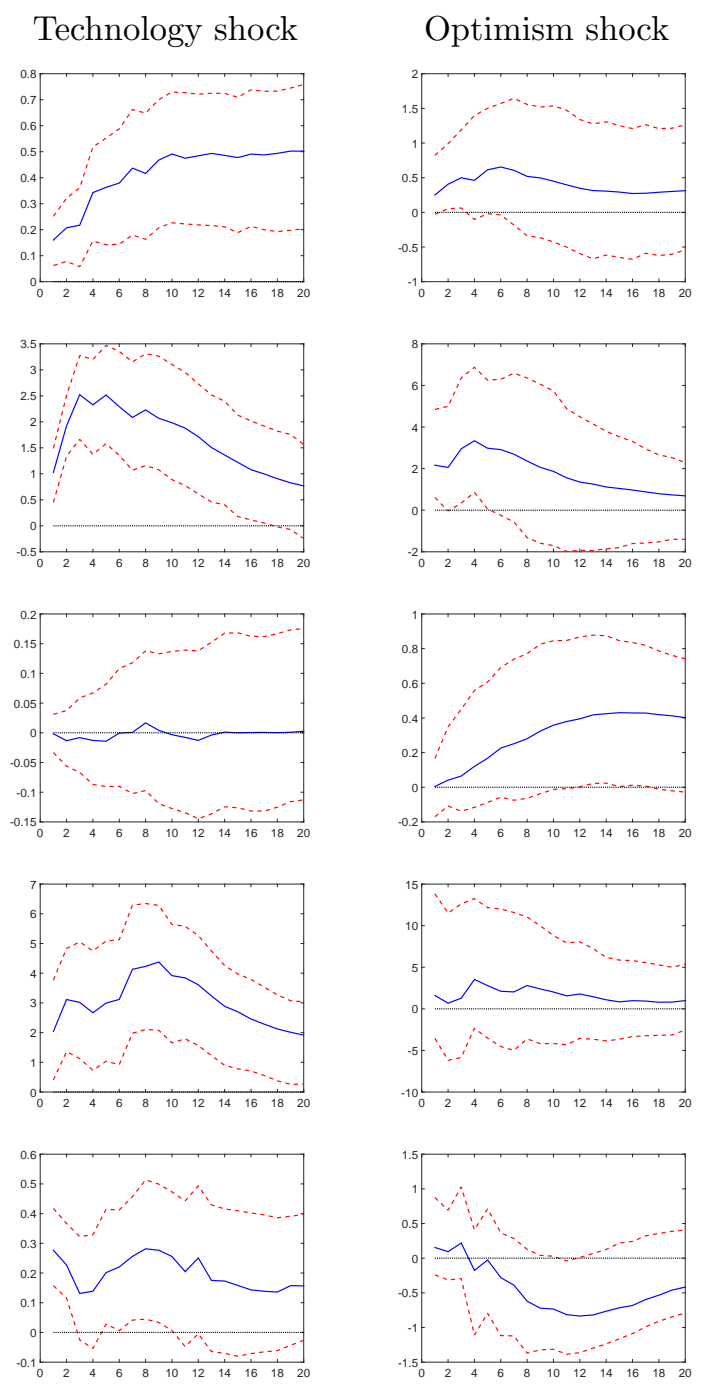

Figure 4: Impulse responses to productivity and optimism shock: alternative variables. Notes: left panel shows results for baseline identification; right panel shows results for identification based on sign restrictions (see section 4.1 as well as Figures 2 and 3 for further details). TFP (Total factor productivity): cumulative growth rates.

the question that motivates our analysis: namely, to what extent are optimism shocks an autonomous source of business cycle fluctuations. In order to gauge their contribution to economic fluctuations we compute a forecast error variance decomposition. Table 4 reports the results. We find that technology are a somewhat more important source of nowcast errors (top panel), with optimism shocks accounting for about 40 percent of forecast error 
Table 4: Forecast error variance decomposition

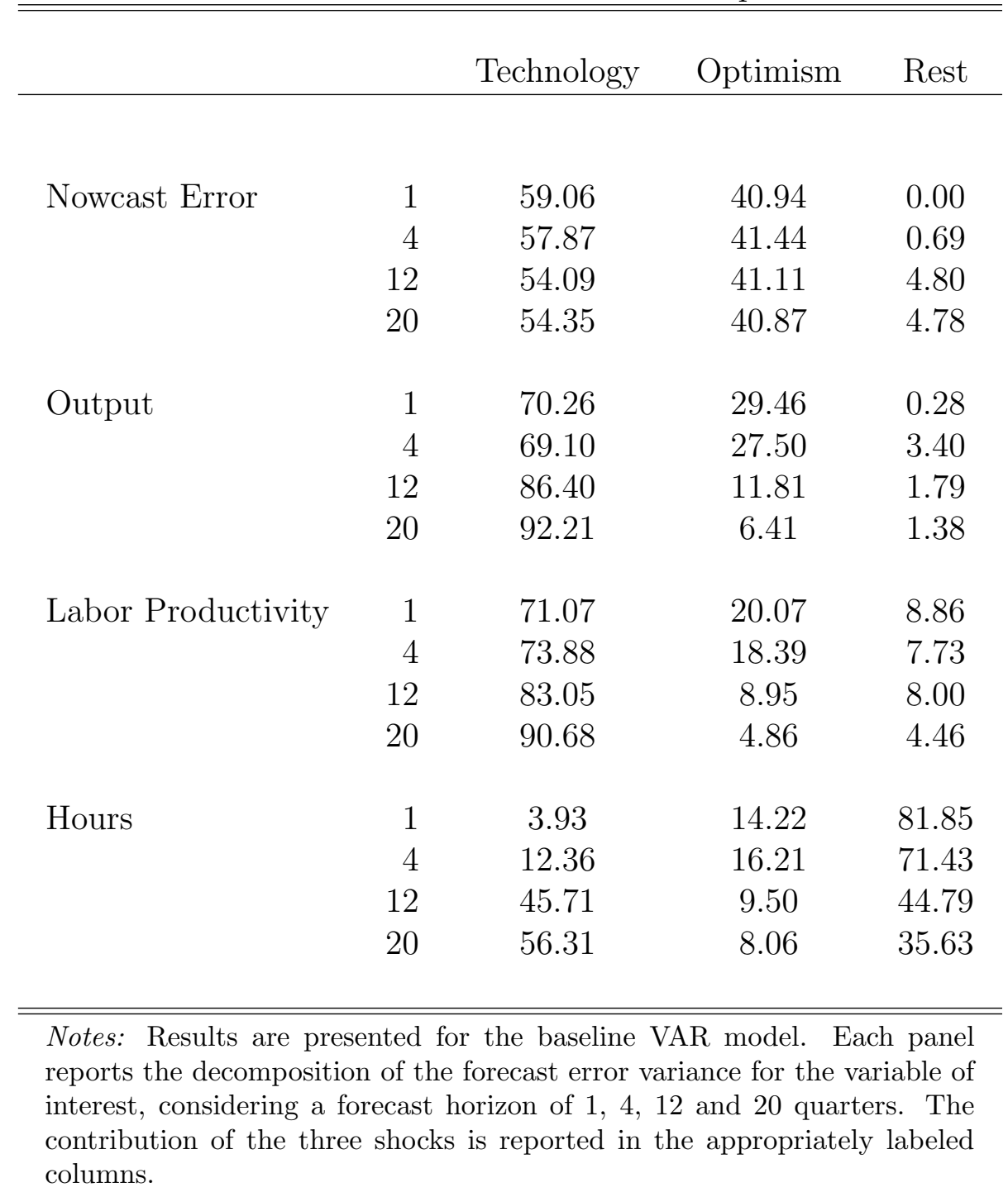

variance, irrespective of the forecast horizon. Regarding output (second panel), technology shocks account for the bulk of fluctuations, yet optimism shocks also contribute substantially. In the short run their contribution amounts to almost 30 percent. In the short run, technology shocks dominate optimism shock as a driving force for variations in labor productivity, while the opposite holds for hours. ${ }^{29}$

These findings are in a similar order of magnitude than those reported by Blanchard et al. (2013). They estimate a medium-scale DSGE model featuring "noise shocks". These

\footnotetext{
${ }^{29}$ Under the alternative identification scheme based on long run restrictions, we find that optimism shocks contribute even more strongly to variations in hours, and less so to those of productivity. Results are available on request.
} 
shocks are structurally identical to optimism shocks as defined in the present paper and account for about 20 percent of short-run output volatility. ${ }^{30}$ Instead, Barsky and Sims (2012), estimating a fully specified DSGE model through indirect inference methods, find that "animal spirit" shocks account for almost none of the volatility of output. While their animal spirit shock is conceptually closely related to optimism shocks, it is restricted to pertain to future productivity (growth) only. Moreover, their analysis is centered around innovations to consumer confidence, which they find to reflect news rather than animal spirits. Once we rotate their time series of confidence innovations as a third variable into our VAR model, we find it to be mostly driven by the "rest" shock. ${ }^{31}$ This finding is consistent with the results of Barsky and Sims (2012) insofar as the rest shock will also contain anticipated technology shocks under our identification scheme.

\subsection{Sensitivity analysis}

We conduct a number of experiments to explore the robustness of our results. First, we consider alternative measures of the nowcast error, which is key to our identification strategy. Our baseline VAR is estimated on nowcast errors computed on the basis of first-release data. Results in Section 2 suggest that nowcast errors based on final-release data may differ somewhat. We therefore estimate our VAR model while replacing the first-release nowcast error with the final-release nowcast error (baseline identification). The estimated impulse responses to technology and optimism shocks obtained under this specification are shown in the left panel of Figure 5, confirming our findings for the baseline VAR model reported in Figure 2.

In what follows we explore to what extent results are robust once we consider a different sampling frequency, as our identification strategy relies on assumptions regarding the available information at the time forecasters are asked to predict current output growth.

\footnotetext{
${ }^{30}$ In a similar exercise, Hürtgen (2014) obtains a value of 14 percent. While conceptually distinct, it might be noteworthy that the contribution of "noisy news" to the short-run fluctuations of output amounts to some 50 percent according to Forni et al. (2014), comparable to that of the single most important business cycle shock constructed by Angeletos et al. (2014).

${ }^{31}$ Specifically, we consider the series for confidence innovations of Barsky and Sims (2012), which is based on the Michigan Survey of Consumers. Confidence innovations are computed on the basis of their VAR model and their orthogonalization with confidence ordered first. We include confidence innovations in our baseline VAR model (using the longest overlapping sample), replacing the time series for hours worked. Computing a forecast error variance decomposition, we find that about two thirds of the shortrun variance of confidence innovations is due to the rest shock, while the optimism shock accounts for less than 5 percent. Moreover, we find that only the rest shock has a significant impact on confidence innovations. It is positive and short-lived.
} 

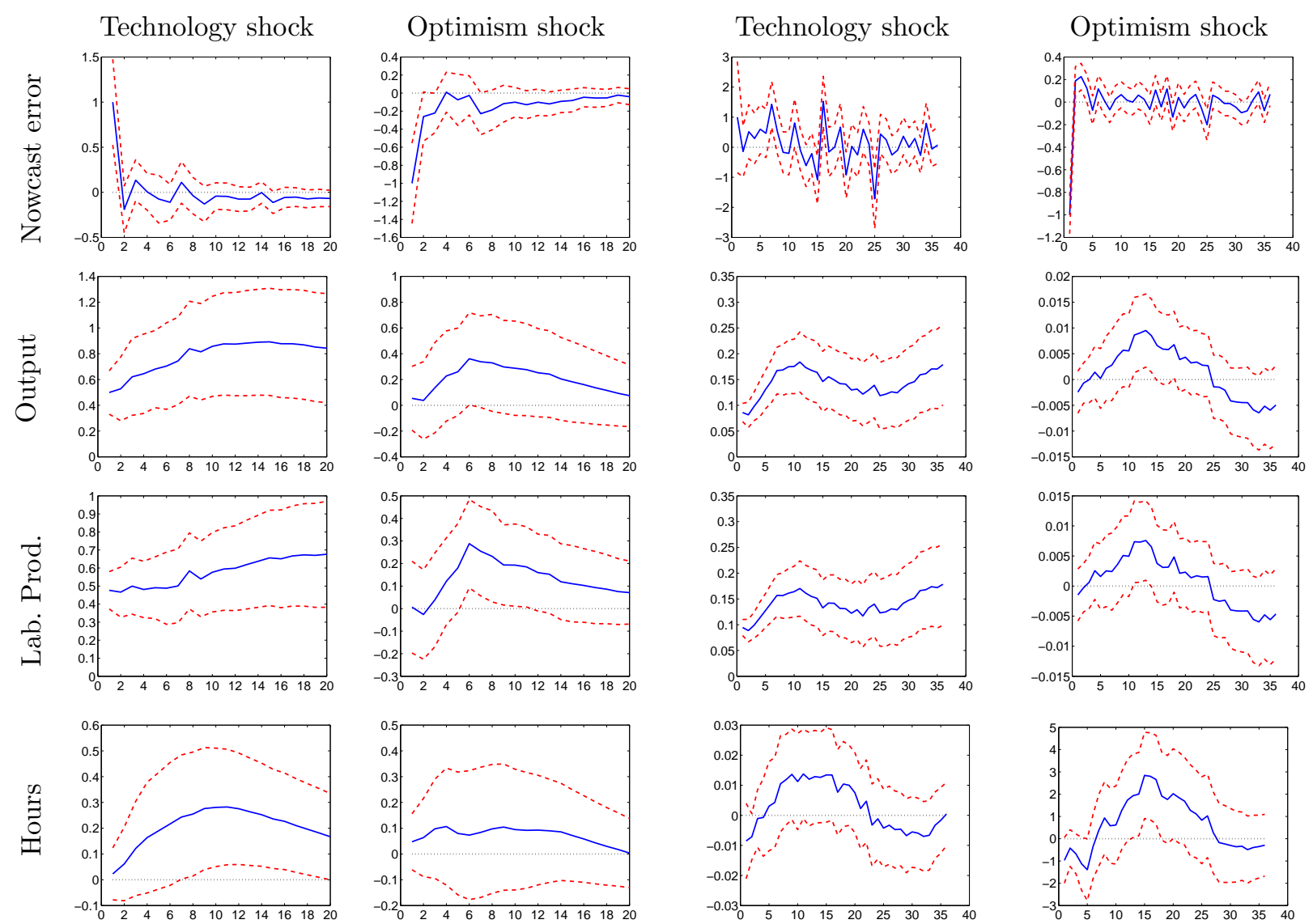

Figure 5: Impulse responses to technology and optimism shock: Sensitivity analysis I. Notes: results based on baseline identification scheme; left panel shows results for nowcast error based on final-release data; right panel shows results for nowcast error based on monthly data for industrial production (sample: 1996M10-2013M12); horizontal axis measures months.

Specifically, forecasters are assumed to have no information regarding current innovations to output growth. Due to the frequency of releases of GDP data, our baseline VAR model is estimated on quarterly observations. In order to construct an alternative monthly measure of the nowcast error, we use data for industrial production and an appropriate survey of professional forecasters by Bloomberg. ${ }^{32}$ Results are shown in the right panel of Figure 5.

\footnotetext{
${ }^{32}$ The Bloomberg survey forecasts are available since 1996M10. We consider data up to 2013M12. The series on monthly hours is the index of aggregate weekly hours of production for workers in manufacturing from the Bureau of Labor Statistics, while the corresponding growth rate of labor productivity is the difference in the growth rates of the volume index of industrial production, obtained from the Federal Reserve, and hours. We estimate the VAR with 24 lags, that is, we include two years as in the baseline model estimated on quarterly data.
} 

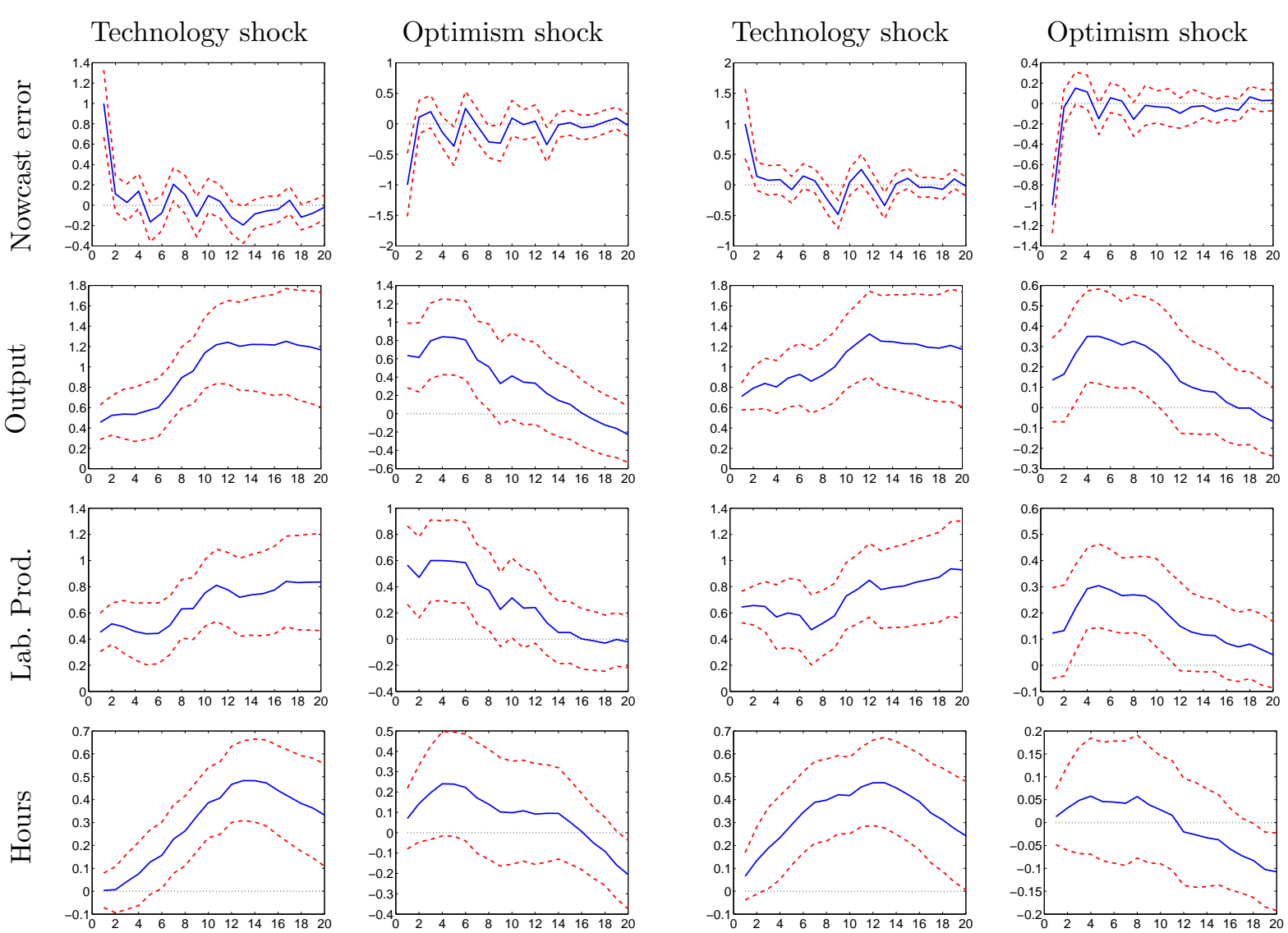

Figure 6: Impulse responses to technology and optimism shock: Sensitivity analysis II. Notes: left panel shows results for VAR model on the baseline sample but with twelve lags, see Figure 2; right panel shows results for baseline VAR model estimated on sample starting in 1968Q4 with twelve Lags.

From a qualitative point of view, they are in line with those obtained for the baseline VAR model, despite considerable differences in the sample (1996M10-2013M12), data frequency, and the measure of economic activity.

Next, we are turning to alternative assumptions regarding the number of lags included in the VAR model and the sample period. Results are shown in Figure 6. The left panel shows results for the model estimated on twelve lags. They are very similar to those of the baseline specification (see Figure 2). The right panel shows results for the longest possible sample given data availability: 1968Q4-2013Q4. Again, results are fairly similar to those obtained under the baseline specification.

Finally, we explore the robustness of our results with respect to alternative assumptions 
Hours in first differences
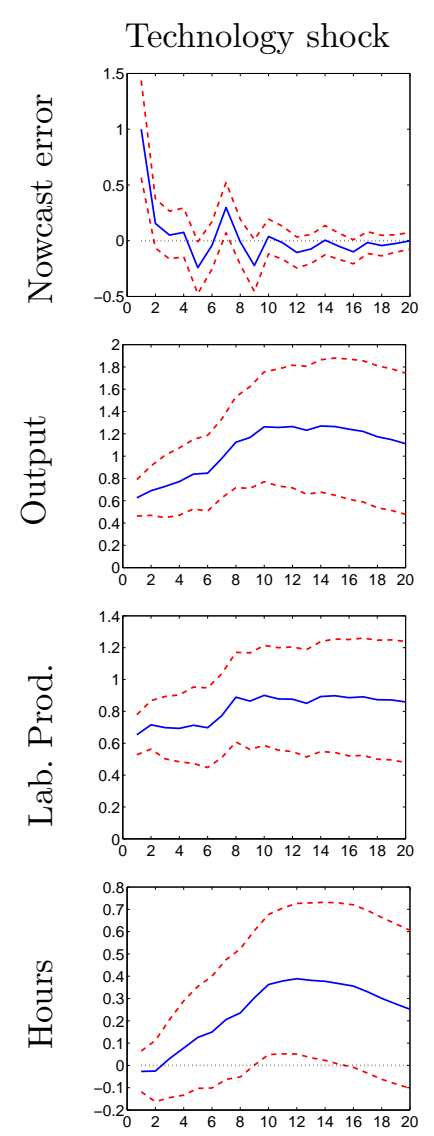

Optimism shock
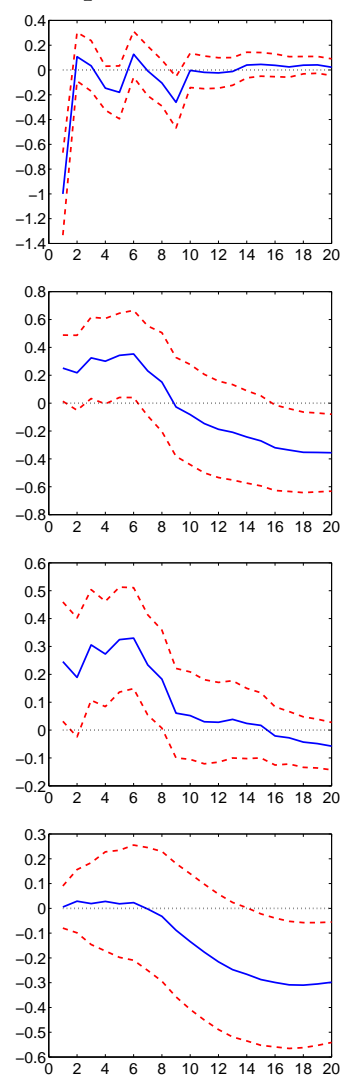

Hours w/o linear trend
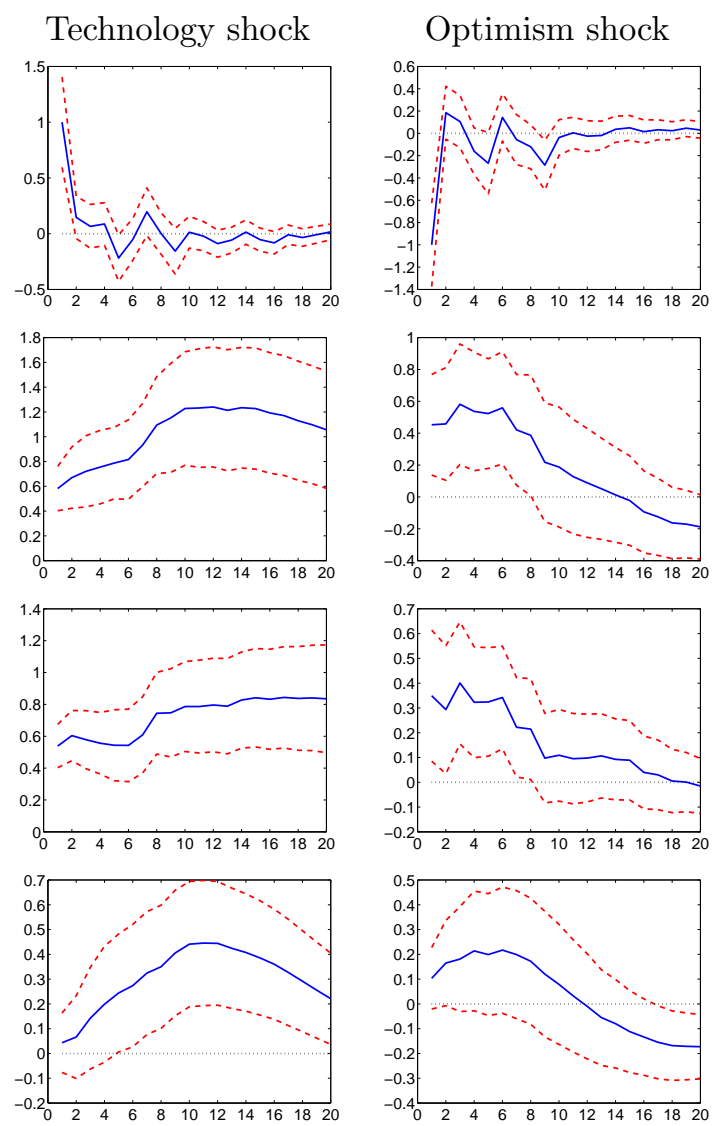

Figure 7: Impulse responses to technology and optimism shock: Sensitivity analysis III. Notes: left panel shows results for hours in first differences, right panel for specification with a exogenous linear trend.

regarding potential trends in the time series for hours worked. This issue has received considerable attention in the literature, as some studies found the trend specification to be crucial for the sign of the response of hours worked to a technology shock. This is not the case in our setup. Recall that we do not allow for a trend in hours in our baseline specification. Figure 7 shows results for a specification where hours enter in first differences (left panel) and for a linear trend specification with a linear trend (right panel). ${ }^{33}$ Our results may therefore also shed some light on the so-called "hours puzzle" (see Galí 1999, Francis and Ramey 2005, and Chari et al. 2008, among others). Given that hours

\footnotetext{
${ }^{33}$ Here hours entering the VAR model either in levels, first differences or detrended with a linearquadratic trend are commonly considered to be the most plausible specifications, see Galí and Rabanal (2005). Our results are also robust to detrending hours with a one-sided HP-filter.
} 
unambiguously rise after (unexpected) technology shocks under our identification scheme, a decline in hours documented elsewhere is likely due to technology innovations which have no effect on nowcast errors. This, in turn, may be the result of innovations to technology that have been anticipated.

\section{Conclusion}

To what extent are changes of expectations an autonomous source of business cycle fluctuations? In this paper, we pursue a new approach to address this question. Barsky and Sims (2012) and Blanchard et al. (2013) estimate fully-specified DSGE models to quantify the importance of "noise" or "undue optimism", reaching quite different conclusions. We employ a structural VAR model instead, thereby imposing less structure on the data. Yet, as shown by Blanchard et al. (2013), identifying the effects of optimism shocks within VARs constitutes a formidable challenge.

Our empirical strategy is based on an ex-post informational advantage over market participants. Namely, we compute nowcast errors regarding current output growth as the difference between actual output growth and the median forecast in the Survey of Professional Forecasters. Nowcast errors are a reduced-form measure of misperceptions, which we show to respond systematically to innovations in total factor productivity. However, we find them not to be significantly affected by policy innovations or uncertainty shocks which are, in some sense, contemporaneously observable by market participants.

Drawing on Lorenzoni (2009), we put forward a stylized business cycle model which gives rise to nowcast errors due to technology and optimism shocks, as agents do not observe output contemporaneously. Shocks which are common information do not generate a nowcast error. Importantly, we use this model to show that optimism shocks can be recovered from time-series data on nowcast errors.

Given these results, we estimate a VAR model on U.S. time series including the nowcast error, labor productivity, and hours worked for the period 1983Q1-2013Q4. We identify unanticipated shocks to technology and optimism shocks by combining short and longrun restrictions. Specifically, we assume for our baseline identification scheme that only optimism shocks and technology shocks generate nowcast errors instantaneously and technology shocks are the only shocks affecting labor productivity in the long run. We find that both shocks have a sizable and persistent effect on output, yet their effect on the nowcast error differs fundamentally. We find that technology shocks induce a positive 
nowcast error, that is, growth is higher than expected. Optimism shocks, on the other hand, induce a negative nowcast error, that is, growth is lower than expected. While this result is quite intuitive, it is remarkable because it implies that the correlation of nowcast errors and economic activity conditional on optimism shocks changes sign relative to the unconditional correlation.

According to the forecast error variance decomposition, the contribution of optimism shocks amounts to almost 30 percent of output fluctuations in the short run. As in Blanchard et al. (2013) we thus find a sizeable contribution of optimism shocks to short-run fluctuations. Differences relative to Barsky and Sims (2012) are likely to reflect differences in the informational content of the nowcast error of current output growth on the one hand and of consumer sentiment data on the other.

\section{References}

Angeletos, G.-M., Collard, F., and Dellas, H. (2014). Quantifying confidence. mimeo.

Angeletos, G.-M. and La'O, J. (2013). Sentiments. Econometrica, 81:739-779.

Arias, J. E., Rubio-Ramírez, J. F., and Waggoner, D. F. (2014). Inference based on SVARs identified with sign and zero restrictions: Theory and applications. mimeo.

Bachmann, R. and Sims, E. R. (2012). Confidence and the transmission of government spending shocks. Journal of Monetary Economics, 59:235-249.

Balleer, A. and Enders, Z. (2013). Expansionary and contractionary technology improvements. Manuscript, University of Heidelberg.

Barsky, R. B. and Sims, E. R. (2011). News shocks and business cycles. Journal of Monetary Economics, 58:273-289.

Barsky, R. B. and Sims, E. R. (2012). Information, animal spirits, and the meaning of innovations in consumer confidence. American Economic Review, 52:1343-1377.

Basu, S., Fernald, J. G., and Kimball, M. S. (2006). Are technology improvements contractionary? American Economic Review, 96(5):1418-1448.

Beaudry, P., Nam, D., and Wang, J. (2011). Do mood swings drive business cycles and is it rational? NBER Working paper 17651. 
Beaudry, P. and Portier, F. (2004). An exploration into Pigou's theory of cycles. Journal of Monetary Economics, 51:1183-1216.

Beaudry, P. and Portier, F. (2006). Stock prices, news, and economic fluctuations. American Economic Review, 96:1293-1307.

Blanchard, O. (1993). Consumption and the recession of 1990-91. American Economic Review, 83:270-274.

Blanchard, O., L'Huillier, J.-P., and Lorenzoni, G. (2013). News, noise, and fluctuations: An empirical investigation. American Economic Review, 103:3045-70.

Bloom, N. (2009). The impact of uncertainty shocks. Econometrica, 77(3):623-685.

Caroll, C. D., Fuhrer, J. C., and Wilcox, D. W. (1994). Does consumer sentiment forecast household spending? If so, why? American Economic Review, 84(5):1397-1408.

Chari, V., Kehoe, P. J., and McGrattan, E. R. (2008). Are structural VARs with long-run restrictions useful in developing business cyclce theory? Journal of Monetary Economics, $55: 1337-1352$.

Clarida, R., Galí, J., and Gertler, M. (2000). Monetary policy rules and macroeconomic stability: Evidence and some theory. Quarterly Journal of Economics, 115:147-180.

Coibion, O. and Gorodnichenko, Y. (2012a). Information rigidity and the expectations formation process: A simple framework and new facts. IMF Working Paper 12/296.

Coibion, O. and Gorodnichenko, Y. (2012b). What can survey forecasts tell us about information rigidities? Journal of Political Economy, 120(1):116-159.

Croushore, D. (1993). Introducing: the survey of professional forecasters. Business Review, 6.

De Graeve, F. and Westermark, A. (2013). Un-truncating VARs. Riksbank Research Paper Series No. 102.

Enders, Z., Mller, G. J., and Scholl, A. (2011). How do fiscal and technology shocks affect real exchange rates? New evidence for the united states. Journal of International Economics, 83:53-69. 
Faust, J., Rogers, J. H., and Wright, J. H. (2005). News and noise in G-7 GDP announcements. Journal of Money, Credit and Banking, 37(3):403-419.

Fernald, J. (2012). A quarterly, utilization-adjusted series on total factor productivity. Manuscript, Federal Reserve Bank of San Francisco.

Fernández-Villaverde, J., Rubio-Ramírez, J. F., Sargent, T., and Watson, M. W. (2007). ABCs (and Ds) of understanding VARs. American Economic Review, 97(3):1021 - 1026.

Forni, M., Gambetti, L., Lippi, M., and Sala, L. (2014). Noisy news in business cycles. mimeo.

Francis, N. and Ramey, V. A. (2005). Is the technology-driven real business cycle hypothesis dead? Shocks and aggregate fluctuations revisited. Journal of Monetary Economics, 52(8):1379 - 1399 .

Galí, J. (1999). Technology, employment, and the business cycle: Do technology shocks explain aggregate fluctuations? American Economic Review, 89:249-271.

Galí, J. and Rabanal, P. (2005). Technology shocks and aggregate fluctuations: How well does the real business cycle model fit postwar U.S. data? In NBER Macroeconomics Annual 2004, volume 19, pages 225-318. National Bureau of Economic Research, Inc.

Hürtgen, P. (2014). Consumer misperceptions, uncertain fundamentals, and the business cycle. Journal of Economic Dynamics and Control, 40:279-292.

Jaimovic, N. and Rebelo, S. (2009). Can news about the future drive the business cycle? American Economic Review, 96:1097-1118.

Jordà, O. (2005). Estimation and inference of impulse responses by local projections. American Economic Review, 95:161-182.

Keynes, J. M. (1936). The General Theory of Employment, Interest, and Money. Edition Harvest/Harcourt Brace 1964, Orlando, Florida.

Leduc, S. and Sill, K. (2013). Expectations and economic fluctuations: An analysis using survey data. The Review of Economics and Statistics, 95:1352-1367.

Lorenzoni, G. (2009). A theory of demand shocks. American Economic Review, 99:20502084. 
McConnell, M. M. and Perez-Quiros, G. (2000). Output fluctuations in the United States: What has changed since the early 1980s? American Economic Review, 90:1464-1476.

Mora, J. V. R. and Schulstad, P. (2007). The effect of GNP announcements on fluctuations of GNP growth. European Economic Review, 51:1922-1940.

Nordhaus, W. D. (1987). Forecasting efficiency: Concepts and applications. The Review of Economics and Statistics, 69(4):667-674.

Oh, S. and Waldman, M. (1990). The macroeconomic effects of false announcements. The Quarterly Journal of Economics, 105:1017-1034.

Peersman, G. (2005). What caused the early millennium slowdown? Evidence based on Vector Autoregressions. Journal of Applied Econometrics, 20:185-207.

Pigou, A. C. (1927). Industrial Fluctuations. Macmillan.

Ramey, V. (2014). Defense news shocks, 1889 - 2013: Estimates based on news sources. Mimeo.

Romer, C. D. and Romer, D. H. (2004). A new measure of monetary shocks: Derivation and implications. American Economic Review, 94(4):1055-1084.

Romer, C. D. and Romer, D. H. (2010). The macroeconomic effects of tax changes: Estimates based on a new measure of fiscal shocks. American Economic Review, 100(3):763801.

Schmitt-Grohé, S. and Uribe, M. (2012). What's news in business cycles? Econometrica, 80:2733-2764.

Stark, T. and Croushore, D. (2002). Forecasting with a real-time data set for macroeconomists. Journal of Macroeconomics, 24(4):507-531.

Uhlig, H. (2005). What are the effects of monetary policy on output?resul ts from an agnostic identification procedure. Journal of Monetary Economics, 52:381-419.

Zarnowitz, V. (1985). Rational expectations and macroeconomic forecasts. Journal of Business \& Economic Statistics, 3(4):293-311. 


\section{Appendix}

In Appendix B, we provide the proofs for Propositions 1-3 in Section 3. In a preliminary step, we outline the model solution and key equilibrium relationships in Appendix A. Throughout, we consider a log-linear approximation to the equilibrium conditions of the model. Small-scale letters indicate percentage deviations from steady state.

\section{A Model solution}

We solve the model by backward induction. That is, we start by deriving inflation expectations regarding period $t+1$. Using the result in the Euler equation of the third stage of period $t$ allows us to determine price-setting decisions during stage two. Eventually, we obtain the short-run responses of aggregate variables to unexpected changes in productivity or optimism shocks.

Expectations regarding period $\boldsymbol{t}+1$. Below, $E_{k, t}$ stands for either $E_{j, l, t}$, referring to the information set of producer $j$ on island $l$ at the time of her pricing decisions, or for $E_{l, t}$, referring to the information set of the household on island $l$ at the time of its consumption decision. Variables with only time subscripts refer to economy-wide values. The wage in period $t+1$ is set according to the expected aggregate labor supply

$$
E_{k, t} \varphi l_{t+1}=E_{k, t}\left(w_{t+1}-p_{t+1}-c_{t+1}\right)
$$

This equation is combined with the aggregated production function

$$
E_{k, t} y_{t+1}=E_{k, t}\left(x_{t+1}+\alpha l_{t+1}\right)
$$

the expected aggregate labor demand

$$
E_{k, t}\left(w_{t+1}-p_{t+1}\right)=E_{k, t}\left[x_{t+1}+(1-\alpha) l_{t+1}\right]
$$

and market clearing $y_{t+1}=c_{t+1}$ to obtain $E_{k, t} x_{t+1}=E_{k, t} y_{t+1}=E_{k, t} c_{t+1}$. Furthermore, the expected Euler equation, together with the Taylor rule, is

$$
E_{k, t} c_{t+1}=E_{k, t}\left(c_{t+2}+\pi_{t+2}-\psi \pi_{t+1}\right) .
$$


Agents expect the economy to be in a new steady state tomorrow $\left(E_{k, t} c_{t+1}=E_{k, t} c_{t+2}\right)$, given the absence of state variables other than technology, which follows a unit root process. Ruling out explosive paths yields

$$
E_{k, t} \pi_{t+2}=E_{k, t} \pi_{t+1}=0
$$

Stage three of period $\boldsymbol{t}$. After prices are set, each household observes $n$ prices in the economy. Since the productivity signal is public, the productivity level $a_{j, l, t}=a_{l, t}$ - which is the same for all producers $j \in[0,1]$ on island $l$-can be inferred from each price $p_{j, l, t}$ of the good from producer $j$ on island $l$. Hence, household $l$ forms its expectations about the change in aggregate productivity according to

$$
E_{l, t} \Delta x_{t}=\rho_{x}^{h} s_{t}+\delta_{x}^{h} \hat{a}_{l, t}
$$

where $\hat{a}_{l, t}$ is the average over the realizations of $a_{m, t}-x_{t-1}$ for each location $m$ in household l's sample. The coefficients $\rho_{x}^{h}$ and $\delta_{x}^{h}$ are equal across households and depend on $n, \sigma_{e}^{2}, \sigma_{\varepsilon}^{2}$, and $\sigma_{\eta}^{2}$ in the following way:

$$
\rho_{x}^{h}=\underbrace{\frac{\sigma_{\eta}^{2} / n}{\sigma_{e}^{2}+\sigma_{\eta}^{2} / n+\frac{\sigma_{e}^{2} \sigma_{\eta}^{2} / n}{\sigma_{\varepsilon}^{2}}}}_{\rightarrow 0 \text { if } n \rightarrow \infty}, \quad \delta_{x}^{h}=\underbrace{\frac{\sigma_{e}^{2}}{\sigma_{e}^{2}+\sigma_{\eta}^{2} / n+\frac{\sigma_{e}^{2} \sigma_{\eta}^{2} / n}{\sigma_{\varepsilon}^{2}}}}_{\rightarrow 1 \text { if } n \rightarrow \infty} .
$$

Producers, on the other hand, only observe the signal and their own productivity. They thus form expectations according to

$$
E_{j, l, t} \Delta x_{t}=\rho_{x}^{p} s_{t}+\delta_{x}^{p}\left(a_{l, t}-x_{t-1}\right)
$$

with

$$
\rho_{x}^{p}=\frac{\sigma_{\eta}^{2}}{\sigma_{e}^{2}+\sigma_{\eta}^{2}+\frac{\sigma_{\eta}^{2} \sigma_{e}^{2}}{\sigma_{\varepsilon}^{2}}} \quad \delta_{x}^{p}=\frac{\sigma_{e}^{2}}{\sigma_{e}^{2}+\sigma_{\eta}^{2}+\frac{\sigma_{\eta}^{2} \sigma_{e}^{2}}{\sigma_{\varepsilon}^{2}}}
$$

such that $\delta_{x}^{h}>\delta_{x}^{p}$ because of the higher information content of households' observations. Consumption follows an Euler equation with household-specific inflation, as only a subset of goods is bought. Agents expect no differences between households for $t+1$, such that expected aggregate productivity and the overall price level impact today's consumption. 
Using additionally $E_{l, t} p_{t+1}=E_{l, t} p_{t}$ and $E_{l, t} x_{t+1}=E_{l, t} x_{t}$ gives

$$
c_{l, t}=E_{l, t} x_{t}+E_{l, t} p_{t}-p_{l, t}-r_{t}
$$

Similar to the updating formula for technology, households use their available information to form an estimate about the aggregate price level $p_{t}$ according to

$$
E_{l, t} p_{t}=\rho_{p}^{h} s_{t}+\delta_{p}^{h} \hat{a}_{l, t}+\kappa_{p}^{h} w_{t}+\tau_{p}^{h} x_{t-1}-\eta_{p}^{h} r_{t}
$$

Combining the above this gives

$$
c_{l, t}=\left(1+\tau_{p}^{h}\right) x_{t-1}+\rho_{x p}^{h} s_{t}+\delta_{x p}^{h} \hat{a}_{l, t}+\kappa_{p}^{h} w_{t}-\left(1+\eta_{p}^{h}\right) r_{t}-p_{l, t},
$$

where $\rho_{x p}^{h}=\rho_{x}^{h}+\rho_{p}^{h}$ and $\delta_{x p}^{h}=\delta_{x}^{h}+\delta_{p}^{h}$. We will solve for the undetermined coefficients below.

Stage two of period $t$. During the second stage, firms obtain idiosyncratic signals about their productivity. Below, the index $\tilde{p}_{l, t}$ is the average price index of customers visiting island $l$. If customers bought on all (that is, infinitely many) islands in the economy, it would correspond to the overall price level. Since consumers only buy on a subset of islands, the price of their own island has a non-zero weight in their price index, which is taken into account further below. Firms set prices according to

$$
\begin{aligned}
p_{j, l, t} & =w_{t}+\frac{1-\alpha}{\alpha} E_{j, l, t} y_{j, l, t}-\frac{1}{\alpha} a_{l, t} \\
& \equiv k^{\prime}+k_{1}^{\prime} E_{j, l, t} \tilde{p}_{l, t}+k_{2}^{\prime} E_{j, l, t} y_{t}-k_{3}^{\prime} a_{l, t}
\end{aligned}
$$

with

$k^{\prime}=\frac{\alpha}{\alpha+\gamma(1-\alpha)} w_{t} \quad k_{1}^{\prime}=\frac{\gamma(1-\alpha)}{\alpha+\gamma(1-\alpha)} \quad k_{2}^{\prime}=\frac{1-\alpha}{\alpha+\gamma(1-\alpha)} \quad k_{3}^{\prime}=\frac{1}{\alpha+\gamma(1-\alpha)}$.

Evaluating the expectation of firm $j$ about aggregate output in period $t$, using equation (A.4), results in

$$
E_{j, l, t} y_{t}=\kappa^{h}+\rho_{x p}^{h} s_{t}+\delta_{x p}^{h} E_{j, l, t}\left(\frac{1}{n} a_{l, t}+\frac{n-1}{n} E_{j, l, t} x_{t}-x_{t-1}\right)-\left(\frac{1}{n} p_{j, l, t}+\frac{n-1}{n} E_{j, l, t} p_{t}\right),
$$


where $\kappa^{h}=\left(1+\tau_{p}^{h}\right) x_{t-1}-\left(1+\eta_{p}^{h}\right) r_{t}+\kappa_{p}^{h} w_{t}$ contains only publicly available information. Furthermore, it is taken into account that productivity of island $l$ has a non-zero weight in the sample of productivity levels observed by consumers visiting island $l$. Note that producers still take the price index of the consumers as given, since they buy infinitely many goods on the same island. Inserting this in the above pricing equation yields (here, $p_{t}$ is the average of the prices charged by producers of all other islands, which is the overall price index as there are infinitely many locations)

$$
p_{j, l, t} \equiv k+k_{1} E_{j, l, t} p_{t}+\tilde{k} s_{t}-k_{3} a_{l, t}
$$

with

$$
\Xi=1-\frac{1}{n}\left(k_{1}^{\prime}-k_{2}^{\prime}\right) \quad k=\frac{1}{\Xi}\left\{k^{\prime}+k_{2}^{\prime} \kappa^{h}+\frac{k_{2}^{\prime} \delta_{x p}^{h}}{n}\left[(n-1)\left(1-\delta_{x}^{p}\right)-1\right] x_{t-1}\right\}
$$

$k_{1}=\frac{n-1}{n \Xi}\left(k_{1}^{\prime}-k_{2}^{\prime}\right) \quad \tilde{k}=\frac{k_{2}^{\prime}}{\Xi}\left(\rho_{x p}^{h}+\delta_{x p}^{h} \rho_{x}^{p} \frac{n-1}{n}\right) \quad k_{3}=\frac{1}{\Xi}\left\{k_{3}^{\prime}+\frac{k_{2}^{\prime} \delta_{x p}^{h}}{n}\left[(n-1) \delta_{x}^{p}-1\right]\right\}$.

Note that according to (A.5), $0<k_{1}^{\prime}-k_{2}^{\prime}<1$ because $0<\alpha<1$ and $\gamma>1$. According to the definition of $k_{1}$ in (A.6), this implies (observe that $n>1$ )

$$
0<k_{1}<1
$$

Aggregating over all producers gives the aggregate price index

$$
p_{t}=k+k_{1} \bar{E}_{t} p_{t}+\tilde{k} s_{t}-k_{3} x_{t}
$$

where $\int a_{l, t} d l=x_{t}$ and $\bar{E}_{t} p_{t}=\iint E_{j, l, t} p_{t} d j d l$ is the average expectation of the price level. The expectation of firm $j$ of this aggregate is therefore

$$
\begin{aligned}
E_{j, l, t} p_{t} & =k+\tilde{k} s_{t}-k_{3} E_{j, l, t} x_{t}+k_{1} E_{j, l, t} \bar{E}_{t} p_{t} \\
& =k+\left(\tilde{k}-k_{3} \rho_{x}^{p}\right) s_{t}-k_{3} \delta_{x}^{p} a_{l, t}-k_{3}\left(1-\delta_{x}^{p}\right) x_{t-1}+k_{1} E_{j, l, t} \bar{E}_{t} p_{t} .
\end{aligned}
$$

Inserting the last equation into (A.6) gives

$$
p_{j, l, t}=k+k_{1} k-k_{1} k_{3}\left(1-\delta_{x}^{p}\right) x_{t-1}+\left[\tilde{k}+k_{1}\left(\tilde{k}-k_{3} \delta_{x}^{p}\right)\right] s_{t}-\left(k_{3}+k_{1} k_{3} \delta_{x}^{p}\right) a_{t}^{j}+k_{1}^{2} E_{j, l, t} \bar{E}_{t} p_{t} .
$$


To find $E_{j, l, t} \bar{E}_{t} p_{t}$, note that firm $j$ 's expectations of the average of (A.7) are $E_{j, l, t} \bar{E}_{t} p_{t}=k-k_{3}\left(1-\delta_{x}^{p}\right)\left(1+\delta_{x}^{p}\right) x_{t-1}+\left(\tilde{k}-k_{3} \rho_{x}^{p}-k_{3} \delta_{x}^{p} \rho_{x}^{p}\right) s_{t}-k_{3} \delta_{x}^{p 2} a_{l, t}+k_{1} E_{j, l, t} \bar{E}_{t}^{(2)} p_{t}$, where $\bar{E}^{(2)}$ is the average expectation of the average expectation. The price of firm $j$ is found by plugging the last equation into the second-to-last:

$$
\begin{aligned}
p_{j, l, t}= & \left(k+k_{1} k+k_{1}^{2} k\right)-\left[k_{1} k_{3}\left(1-\delta_{x}^{p}\right)+k_{1}^{2} k_{3}\left(1-\delta_{x}^{p}\right)\left(1+\delta_{x}^{p}\right)\right] x_{t-1} \\
& +\left[\tilde{k}+k_{1}\left(\tilde{k}-k_{3} \rho_{x}^{p}\right)+k_{1}^{2}\left(\tilde{k}-k_{3} \rho_{x}^{p}-k_{3} \delta_{x}^{p} \rho_{x}^{p}\right)\right] s_{t} \\
& -\left(k_{3}+k_{1} k_{3} \delta_{x}^{p}+k_{1}^{2} k_{3} \delta_{x}^{p 2}\right) a_{l, t}+k_{1}^{3} E_{j, l, t} \bar{E}^{(2)} p_{t} .
\end{aligned}
$$

Continuing like this results in some infinite sums

$$
\begin{aligned}
p_{j, l, t}= & k\left(1+k_{1}+k_{1}^{2}+k_{1}^{3} \ldots\right) \\
& -k_{1} k_{3}\left(1-\delta_{x}^{p}\right)\left[1+k_{1}\left(1+\delta_{x}^{p}\right)+k_{1}^{2}\left(1+\delta_{x}^{p}+\delta_{x}^{p 2}\right)+k_{1}^{3}\left(1+\delta_{x}^{p}+\delta_{x}^{p 2}+\delta_{x}^{p 3} \ldots\right)\right] x_{t-1} \\
& +\left[\tilde{k}+k_{1}\left(\tilde{k}-k_{3} \rho_{x}^{p}\right)+k_{1}^{2}\left(\tilde{k}-k_{3} \rho_{x}^{p}-k_{3} \delta_{x}^{p} \rho_{x}^{p}\right)+k_{1}^{3}\left(\tilde{k}-k_{3} \rho_{x}^{p}-k_{3} \rho_{x}^{p} \delta_{x}^{p}-k_{3} \rho_{x}^{p} \delta_{x}^{p 2}\right)+\ldots\right] s_{t} \\
& -k_{3}\left(1+k_{1} \delta_{x}^{p}+k_{1}^{2} \delta_{x}^{p 2}+k_{1}^{3} \delta_{x}^{p 3} \ldots\right) a_{l, t}+k_{1}^{\infty} E_{j, l, t} \bar{E}^{(\infty)} p_{t} .
\end{aligned}
$$

For the terms in the third line we have

$$
\begin{aligned}
& \tilde{k}+k_{1}\left(\tilde{k}-k_{3} \rho_{x}^{p}\right)+k_{1}^{2}\left(\tilde{k}-k_{3} \rho_{x}^{p}-k_{3} \delta_{x}^{p} \rho_{x}^{p}\right)+k_{1}^{3}\left(\tilde{k}-k_{3} \rho_{x}^{p}-k_{3} \rho_{x}^{p} \delta_{x}^{p}-k_{3} \rho_{x}^{p} \delta_{x}^{p 2}\right) \\
& +k_{1}^{4}\left(\tilde{k}-k_{3} \rho_{x}^{p}-k_{3} \rho_{x}^{p} \delta_{x}^{p}-k_{3} \rho_{x}^{p} \delta_{x}^{p 2}-k_{3} \rho_{x}^{p} \delta_{x}^{p 3}\right) \ldots \\
= & \tilde{k}\left(1+k_{1}+k_{1}^{2}+k_{1}^{3} \ldots\right)-\left(k_{1} k_{3} \rho_{x}^{p}+k_{1}^{2} k_{3} \rho_{x}^{p}+k_{1}^{3} k_{3} \rho_{x}^{p} \ldots\right) \\
& -\left(\delta_{x}^{p} k_{1}^{2} k_{3} \rho_{x}^{p}+\delta_{x}^{p} k_{1}^{3} k_{3} \rho_{x}^{p}+\delta_{x}^{p} k_{1}^{4} k_{3} \rho_{x}^{p} \ldots\right)-\left(\delta_{x}^{p 2} k_{1}^{3} k_{3} \rho_{x}^{p}+\delta_{x}^{p 2} k_{1}^{4} k_{3} \rho_{x}^{p}+\delta_{x}^{p 3} k_{1}^{5} k_{3} \rho_{x}^{p} \ldots\right) \ldots \\
= & \tilde{k}\left(1+k_{1}+k_{1}^{2}+k_{1}^{3} \ldots\right)-k_{1} k_{3}\left(\frac{\rho_{x}^{p}}{1-k_{1}}+\frac{\rho_{x}^{p} \delta_{x}^{p} k_{1}}{1-k_{1}}+\frac{\rho_{x}^{p} \delta_{x}^{p 2} k_{1}^{2}}{1-k_{1}} \ldots\right) \\
= & \frac{\tilde{k}}{1-k_{1}}-\frac{k_{1} k_{3} \rho_{x}^{p}}{1-k_{1}}\left(1+\delta_{x}^{p} k_{1}+\delta_{x}^{p 2} k_{1}^{2} \ldots\right) \\
= & \frac{\tilde{k}}{1-k_{1}}-\frac{k_{1} k_{3} \rho_{x}^{p}}{\left(1-k_{1}\right)\left(1-\delta_{x}^{p} k_{1}\right)} .
\end{aligned}
$$


Proceeding similarly with the terms in the second line results in $p_{j, l, t}=\frac{k}{1-k_{1}}-\frac{k_{1}\left(1-\delta_{x}^{p}\right)}{1-k_{1}} \frac{k_{3}}{1-k_{1} \delta_{x}^{p}} x_{t-1}+\frac{1}{1-k_{1}}\left(\tilde{k}-\rho_{x}^{p} \frac{k_{1} k_{3}}{1-k_{1} \delta_{x}^{p}}\right) s_{t}-\frac{k_{3}}{1-k_{1} \delta_{x}^{p}} a_{l, t}+\underbrace{k_{1}^{\infty} \bar{E}_{t}^{(\infty)}}_{\rightarrow 0} p_{t}$.

Setting idiosyncratic technology shocks equal to zero in order to track the effects of aggregate shocks and observing that all firms then set the same price gives

$$
p_{t} \equiv \bar{k}_{1}+\bar{k}_{2} s_{t}+\bar{k}_{3} x_{t}
$$

with

$\bar{k}_{1}=\frac{1}{1-k_{1}}\left[k-\left(1-\delta_{x}^{p}\right) \frac{k_{1} k_{3}}{1-k_{1} \delta_{x}^{p}} x_{t-1}\right] \quad \bar{k}_{2}=\frac{1}{1-k_{1}}\left(\tilde{k}-\rho_{x}^{p} \frac{k_{1} k_{3}}{1-k_{1} \delta_{x}^{p}}\right) \quad \bar{k}_{3}=-\frac{k_{3}}{1-k_{1} \delta_{x}^{p}}$.

To arrive at qualitative predictions for the impact of the structural shocks $\varepsilon_{t}$ and $e_{t}$ on output growth and the nowcast error, we need to determine the sign and the size of $\bar{k}_{3}$. Note that according to (A.6)

$$
-k_{3}=\delta_{x p}^{h} \frac{k_{2}^{\prime}-n k_{3}^{\prime} / \delta_{x p}^{h}+k_{2}^{\prime}(n-1) \delta_{x}^{p}}{n-\left(k_{1}^{\prime}-k_{2}^{\prime}\right)}
$$

where the first part of the nominator can be rewritten, by observing (A.5), as

$$
k_{2}^{\prime}-n k_{3}^{\prime} / \delta_{x p}^{h}=\frac{1-n / \delta_{x p}^{h}-\alpha}{\alpha+\gamma(1-\alpha)} .
$$

Using (A.5) and (A.6) yields

$$
-k_{3}=\delta_{x p}^{h} \frac{(1-\alpha)\left[(n-1) \delta_{x}^{p}+1\right]-n / \delta_{x p}^{h}}{(n-1)[\alpha+\gamma(1-\alpha)]+1} .
$$

Plugging this into the definition of $\bar{k}_{3}$ in (A.8) gives

$$
\bar{k}_{3}=\delta_{x p}^{h} \frac{\frac{(1-\alpha)\left[(n-1) \delta_{x}^{p}+1\right]-n / \delta_{x p}^{h}}{(n-1)[\alpha+\gamma(1-\alpha)]+1}}{1-\delta_{x}^{p} \frac{(n-1)(\gamma-1)(1-\alpha)}{(n-1)[\alpha+\gamma(1-\alpha)]+1}}
$$


To obtain $\delta_{x p}^{h}=\delta_{x}^{h}+\delta_{p}^{h}$, we need to find the undetermined coefficients of equation (A.3). Start by comparing this equation with household l's expectation of equation (A.8):

$$
E_{l, t} p_{t}=\underbrace{\bar{k}_{1}+\bar{k}_{3} x_{t-1}}_{\kappa_{p}^{h} w_{t}+\tau_{p}^{h} x_{t-1}-\eta_{p}^{h} r_{t}}+\underbrace{\left(\bar{k}_{2}+\bar{k}_{3} \rho_{x}^{h}\right)}_{\rho_{p}^{h}} s_{t}+\underbrace{\bar{k}_{3} \delta_{x}^{h}}_{\delta_{p}^{h}} \hat{a}_{l, t} .
$$

Hence, $\delta_{x p}^{h}=\delta_{x}^{h}\left(1+\bar{k}_{3}\right)$. Inserting this into the above expression for $\bar{k}_{3}$ yields

$$
\bar{k}_{3} \equiv-\frac{n / \Upsilon-\delta_{x}^{h} \Psi}{\Phi-\delta_{x}^{h} \Psi}
$$

with

$$
\begin{array}{cc}
\Upsilon=(n-1)[\alpha+\gamma(1-\alpha)]+1>0 & \Psi=(1-\alpha)\left[(n-1) \delta_{x}^{p}+1\right] / \Upsilon>0 \\
\Phi=1-\delta_{x}^{p}(n-1)(\gamma-1)(1-\alpha) / \Upsilon . &
\end{array}
$$

The signs obtain because $n>1,0<\alpha<1, \delta_{x}^{p}>0$, and $\gamma>1$. Observe that $\Psi \Upsilon<n$ because $\delta_{x}^{p} \leq 1$. Hence, $n / \Upsilon-\delta_{x}^{h} \Psi>0$ because

$$
n-\underbrace{\delta_{x}^{h}}_{>0,<1} \underbrace{\Psi \Upsilon}_{<n}>0
$$

implying that the nominator of (A.10) is positive. Turning to the denominator $\Phi-\delta_{x}^{h} \Psi$, observe that $\Phi-\Psi>0$. The denominator of (A.10) is therefore positive as well, and we have $\bar{k}_{3}<0$. Next, consider that $n / \Upsilon<\Phi$ and we obtain

$$
-1<\bar{k}_{3}<0
$$

This is a key result for the derivation of Propositions 1-3, see Appendix B. Multiplying the nominator and the denominator of the fraction in equation (A.10) by $\Upsilon$ and rewriting gives the expression used in Proposition 1.

Stage one of period $\boldsymbol{t}$ As information sets of agents are perfectly aligned during stage one, we use the expectation operator $E_{t}$ to denote stage-one expectations in what follows. Combining the results regarding expectations about inflation in period $t+1$ with the Euler 
equation, the Taylor rule, and the random walk assumption for $x_{t}$ gives

$$
E_{t} y_{t}=E_{t} x_{t}-\psi E_{t} \pi_{t}
$$

Remember that the monetary policy shock realizes after wages are set. Its expected value before wage-setting is zero. Using $E_{t} x_{t}=E_{t} y_{t}$ (which results from combining labor supply and demand with the production function), we obtain

$$
E_{t} \pi_{t}=0 .
$$

Nominal wages are set in line with these expectations. We thus have determinacy of the price level. The central bank also expects zero inflation in the absence of monetary policy shocks. To find the effects of monetary policy shocks on the interest rate, including feedback effects via changes in expected inflation, note that according to equation (A.9)

$$
\bar{k}_{1}+\bar{k}_{3} x_{t-1}=\kappa_{p}^{h} w_{t}+\tau_{p}^{h} x_{t-1}-\eta_{p}^{h} r_{t}
$$

where, observing equations (A.5), (A.6), and (A.8),

$$
\begin{aligned}
\bar{k}_{1}= & \frac{1}{\left(1-k_{1}\right) \Xi}\left[\frac{\alpha}{\alpha+\gamma(1-\alpha)}+k_{2}^{\prime} \kappa_{p}^{h}\right] w_{t}-\frac{k_{2}^{\prime}\left(1+\eta_{p}^{h}\right)}{\left(1-k_{1}\right) \Xi} r_{t} \\
& +\frac{1}{\left(1-k_{1}\right) \Xi}\left\{k_{2}^{\prime}\left(1+\tau_{p}^{h}\right)+k_{2}^{\prime} \delta_{x p}^{h}\left[\frac{n-1}{n}\left(1-\delta_{x}^{p}\right)-1\right]-\frac{\left(1-\delta_{x}^{p}\right) k_{1} k_{3} \Xi}{1-k_{1} \delta_{x}^{p}}\right\} x_{t-1} .
\end{aligned}
$$

We can hence determine the coefficient $\eta_{p}^{h}$ as

$$
-\eta_{p}^{h}=\frac{k_{2}^{\prime}\left(1+\eta_{p}^{h}\right)}{\left(1-k_{1}\right) \Xi}=\frac{\alpha-1}{\alpha}
$$

which is the impact of $r_{t}$ on the price level. To finally determine the response of $r_{t}$, use this insight in the Taylor rule, resulting in

$$
r_{t}=\psi \frac{\alpha-1}{\alpha} r_{t}+\theta_{t}=\frac{\alpha}{\alpha+\psi(1-\alpha)} \theta_{t} .
$$




\section{B Proofs}

Proof of Proposition 1 Aggregating individual Euler equations (A.2) over all individuals, using (A.8), (A.9), and (A.11), gives

$$
\begin{aligned}
y_{t} & =E_{l, t} x_{t}+E_{l, t} p_{t}-p_{t}-r_{t} \\
& =x_{t-1}+\rho_{x}^{h}\left(1+\bar{k}_{3}\right) s_{t}+\left[\delta_{x}^{h}+\bar{k}_{3}\left(\delta_{x}^{h}-1\right)\right] \varepsilon_{t}-\frac{\alpha}{\alpha+\psi(1-\alpha)} \theta_{t} \\
& =x_{t-1}+\underbrace{\rho_{x}^{h}\left(1+\bar{k}_{3}\right)}_{>0} e_{t}+\underbrace{\left[\delta_{x}^{h}+\rho_{x}^{h}-\bar{k}_{3}\left(1-\delta_{x}^{h}-\rho_{x}^{h}\right)\right]}_{>0} \varepsilon_{t} \underbrace{-\frac{\alpha}{\alpha+\psi(1-\alpha)}}_{<0} \theta_{t},
\end{aligned}
$$

where $1-\delta_{x}^{h}-\rho_{x}^{h}>0$ because of (A.1). Note that if households have full information $(n \rightarrow \infty)$, we get $\rho_{x}^{h} \rightarrow 0$ and $\delta_{x}^{h} \rightarrow 1$. Defining $\Omega \equiv-\bar{k}_{3}$, we can write

$$
y_{t}=x_{t-1}+\rho_{x}^{h}(1-\Omega) e_{t}+\left[\left(\delta_{x}^{h}+\rho_{x}^{h}\right)(1-\Omega)+\Omega\right] \varepsilon_{t}-\frac{\alpha}{\alpha+\psi(1-\alpha)} \theta_{t} .
$$

The signs indicated above result from $0<\Omega=-\bar{k}_{3}<1$ (derived in Appendix A), completing the proof.

Proof of Proposition 2 Now consider the nowcast error, where expectations are either those of households or producers, that is, $E_{k, t}$ substitutes for either $E_{j, l, t}$ or $E_{l, t}$, and $\rho^{k}, \delta^{k}$ correspondingly for $\rho^{p}, \delta^{p}$ or $\rho^{h}, \delta^{h}$.

$$
\begin{aligned}
& E_{k, t} y_{t}=x_{t-1}+\rho_{x}^{h}\left(1+\bar{k}_{3}\right) s_{t}+\left[\delta_{x}^{h}+\bar{k}_{3}\left(\delta_{x}^{h}-1\right)\right] E_{k, t} x_{t}-r_{t} \\
&=x_{t-1}+\left\{\rho_{x}^{h}\left(1+\bar{k}_{3}\right)+\left[\delta_{x}^{h}+\bar{k}_{3}\left(\delta_{x}^{h}-1\right)\right] \rho_{x}^{k}\right\} s_{t}+\left[\delta_{x}^{h}+\bar{k}_{3}\left(\delta_{x}^{h}-1\right)\right] \delta_{x}^{k} \varepsilon_{t}-r_{t} . \\
& y_{t}-E_{k, t} y_{t}=-\rho_{x}^{k}\left[\delta_{x}^{h}+\bar{k}_{3}\left(\delta_{x}^{h}-1\right)\right] s_{t}+\left[\delta_{x}^{h}+\bar{k}_{3}\left(\delta_{x}^{h}-1\right)\right]\left(1-\delta_{x}^{k}\right) \varepsilon_{t} \\
&=\underbrace{-\rho_{x}^{k}\left[\delta_{x}^{h}+\bar{k}_{3}\left(\delta_{x}^{h}-1\right)\right]}_{<0} e_{t}+\underbrace{\left[\delta_{x}^{h}+\bar{k}_{3}\left(\delta_{x}^{h}-1\right)\right]}_{>0} \underbrace{\left(1-\delta_{x}^{k}-\rho_{x}^{k}\right)}_{>0} \varepsilon_{t},
\end{aligned}
$$

or

$$
y_{t}-E_{k, t} y_{t}=-\rho_{x}^{k}\left[\delta_{x}^{h}(1-\Omega)+\Omega\right] e_{t}+\left[\delta_{x}^{h}(1-\Omega)+\Omega\right]\left(1-\delta_{x}^{k}-\rho_{x}^{k}\right) \varepsilon_{t} .
$$


The fact that $0<\Omega<1$ (see Appendix A) allows us to determine the signs of the effects of the shocks on the nowcast error.

Proof of Proposition 3 The model can be written in the following state space system:

$$
\begin{aligned}
\tilde{X}_{t+1} & =C \tilde{X}_{t}+D \tilde{V}_{t} \\
\tilde{Y}_{t} & =F \tilde{X}_{t}+G \tilde{V}_{t},
\end{aligned}
$$

with $\tilde{Y}_{t}$ and $\tilde{V}_{t}$ defined in the main text, $C=0, D=I_{3}$, and

$$
\begin{aligned}
F & =\left[\begin{array}{ccc}
0 & 0 & 0 \\
\frac{\Omega-1}{\alpha}(1-\alpha)\left(1-\rho_{x}^{h}-\delta_{x}^{h}\right) & \frac{1-\Omega}{\alpha} \rho_{x}^{h}(1-\alpha) & \frac{\alpha-1}{\alpha+\psi(1-\alpha)} \\
0 & 0 & 0
\end{array}\right] \\
G & =\left[\begin{array}{ccc}
{\left[\delta_{x}^{h}(1-\Omega)+\Omega\right]\left(1-\delta_{x}^{k}-\rho_{x}^{k}\right)} & -\rho_{x}^{k}\left[\delta_{x}^{h}(1-\Omega)+\Omega\right] & 0 \\
\Omega+\frac{1-\Omega}{\alpha}\left[1-(1-\alpha)\left(\rho_{x}^{h}+\delta_{x}^{h}\right)\right] & \frac{\alpha-1}{\alpha} \rho_{x}^{h}(1-\Omega) & \frac{1-\alpha}{\alpha+\psi(1-\alpha)} \\
\frac{(\Omega-1)}{\alpha}\left(1-\delta_{x}^{h}-\rho_{x}^{h}\right) & \frac{1-\Omega}{\alpha} \rho_{x}^{h} & \frac{-1}{\alpha+\psi(1-\alpha)}
\end{array}\right] .
\end{aligned}
$$

The dynamics of the model can then be represented by the following VAR (see FernándezVillaverde et al. 2007 for details):

$$
\tilde{Y}_{t+1}=F \sum_{j=0}^{\infty}\left(C-D G^{-1} F\right)^{j} D G^{-1} \tilde{Y}_{t-j}+G \tilde{V}_{t+1}=F \sum_{j=0}^{\infty}\left(-G^{-1} F\right)^{j} G^{-1} \tilde{Y}_{t-j}+G \tilde{V}_{t+1}
$$

The matrix $F G^{-1}$ results as

$$
F G^{-1}=\left[\begin{array}{ccc}
0 & 0 & 0 \\
0 & 0 & 1-\alpha \\
0 & 0 & 0
\end{array}\right]
$$

such that

$$
F G^{-1} F G^{-1}=0
$$


and we obtain the final $\operatorname{VAR}(1)$ representation ${ }^{34}$

$$
\tilde{Y}_{t+1}=\underbrace{F G^{-1}}_{\equiv A} \tilde{Y}_{t}+\underbrace{G}_{\equiv B} \tilde{V}_{t+1}
$$

Proof of Corollary 1 Using the equations derived in the proof of Proposition 3, the long-run impact matrix can be calculated as $\left(I_{3}-F G^{-1}\right)^{-1} G$, that is

$$
\begin{aligned}
& {\left[\begin{array}{ccc}
1 & 0 & 0 \\
0 & 1 & 1-\alpha \\
0 & 0 & 1
\end{array}\right]\left[\begin{array}{ccc}
{\left[\delta_{x}^{h}(1-\Omega)+\Omega\right]\left(1-\delta_{x}^{k}-\rho_{x}^{k}\right)} & -\rho_{x}^{k}\left[\delta_{x}^{h}(1-\Omega)+\Omega\right] & 0 \\
\Omega+\frac{1-\Omega}{\alpha}\left[1-(1-\alpha)\left(\rho_{x}^{h}+\delta_{x}^{h}\right)\right] & \frac{\alpha-1}{\alpha} \rho_{x}^{h}(1-\Omega) & \frac{1-\alpha}{\alpha+\psi(1-\alpha)} \\
\frac{(\Omega-1)}{\alpha}\left(1-\delta_{x}^{h}-\rho_{x}^{h}\right) & \frac{1-\Omega}{\alpha} \rho_{x}^{h} & \frac{-1}{\alpha+\psi(1-\alpha)}
\end{array}\right] } \\
= & {\left[\begin{array}{lll}
* & * & 0 \\
1 & 0 & 0 \\
* & * & *
\end{array}\right] }
\end{aligned}
$$

where asterisks represent non-zero elements. The middle row captures the long-run impact of the shocks on the level of labor productivity. The short-run impact of $\theta_{t}$ on the nowcast error equals the upper-right entry of $G$; it is zero.

\footnotetext{
${ }^{34}$ Note that the "poor man's invertibility condition" of Fernández-Villaverde et al. (2007) is satisfied as the matrix $-G^{-1} F$ has rank one and therefore at most one non-zero eigenvalue. The trace equals zero, such that all eigenvalues are zero and hence strictly less than unity.
} 